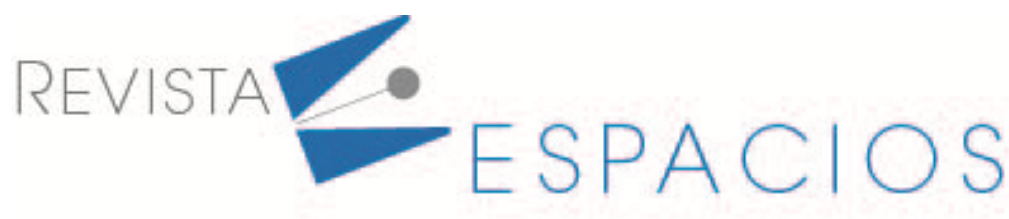

Vol. 42 (08) $2021 \cdot$ Art. 4

Recibido/Received: 04/12/2020 • Aprobado/Approved: 15/03/2021 • Publicado/Published: 30/04/2021

\title{
Análisis de la movilidad urbana en la ciudad de Tulcán, Ecuador
}

\section{Analysis of urban mobility in the city of Tulcán, Ecuador}

MAFLA, Iván G. ${ }^{1}$

BELTRÁN, Daniel M. ${ }^{2}$

MORA, Edwin J. ${ }^{3}$

\section{Resumen}

El presente trabajo muestra los resultados del proyecto de investigación "Modelo de evaluación de sustentabilidad y de optimización de la movilidad y la logística urbanas, en la ciudad de Tulcán Provincia del Carchi". Se analizó la dimensión de movilidad urbana mediante la descripción de zonas por actividad, centros de atracción y generación de viajes, partición modal, uso de transporte público y privado y no motorizado, costos del transporte, propósitos y rutas de viajes, zonas de estacionamiento, flujos, congestión y accidentabilidad.

Palabras clave: movilidad urbana, transporte, viajes.

\begin{abstract}
This work shows the results of the research project "Model for the evaluation of sustainability and optimization of urban mobility and logistics, in the city of Tulcán - Province of Carchi". The urban mobility dimension was analyzed by describing areas by activity, centers of attraction and generation of trips, modal partition, use of public and private and non-motorized transport, transport costs, purposes and routes of trips, parking areas, flows, congestion, and accident rates.
\end{abstract}

Key words: urban mobility, transport, trips.

\section{Introducción}

El desarrollo tecnológico, social, educativo y económico de los países en los últimos años ha tenido un gran crecimiento, debido a que el pensamiento de la sociedad actual está ligado a satisfacer sus necesidades casi de forma inmediata, dejando de lado los aspectos críticos de la sustentabilidad, economía y sociedad pero con conciencia ambiental. La logística y la movilidad urbana juegan un papel importante en este contexto porque permiten la comunicación, la productividad económica y la dinámica comercial para solventar dichas necesidades y mejorar la calidad de vida de los habitantes de los países. Estas actividades se basan fundamentalmente en modos de transporte motorizados no sustentables y privados, cuya operación tiene efectos negativos sobre las condiciones de vida de las personas y la conservación del medio ambiente y sus recursos naturales (Poole Fuller, 2017). El uso de fuentes de energía sustentables y el desarrollo de un sistema de transporte integrado donde se

\footnotetext{
${ }^{1}$ Docente investigador. Carrera de Logística y Transporte. Universidad Politécnica Estatal del Carchi. gabriel.mafla@upec.edu.ec

${ }^{2}$ Docente investigador. Carrera de Logística y Transporte. Universidad Politécnica Estatal del Carchi. daniel.beltran@upec.edu.ec

${ }^{3}$ Docente investigador. Carrera de Logística y Transporte. Universidad Politécnica Estatal del Carchi. jonathan.mora@upec.edu.ec
} 
priorice el manejo de medios públicos y privados no motorizados y eléctricos aparecen en el horizonte como la solución a mediano y largo plazo del problema de la sustentabilidad (Gartor, 2015; GADMT, 2020).

Una movilidad urbana eficiente hace que la ciudad sea más competitiva y para esto es necesario que el sistema de transporte ofertado en infraestructura, vehículos y normativa sea accesible, seguro y suficiente para sus habitantes. Se requiere también una planificación acorde a estos aspectos para optimizar los tiempos de traslado de las personas en el desarrollo de actividades diarias, garantizando siempre la sustentabilidad en relación a un menor impacto sobre la salud, protección del medio ambiente y reducción del número y costos de las externalidades del transporte como congestión, accidentabilidad, daños y desperfectos en la infraestructura y equipos del sistema de transporte (Quintero-González, 2017).

En la ciudad de Tulcán (Ecuador) es evidente el crecimiento poblacional y el desarrollo económico de los últimos años debido a su ubicación geográfica en la frontera con Colombia, el establecimiento de importantes instituciones como la Universidad Politécnica Estatal del Carchi, empresas de transporte de mercancías y varios establecimientos comerciales, que han hecho que varias personas de distintas provincias del país se radiquen en la ciudad, produciéndose un impacto significativo en las características de la infraestructura urbana, flujos vehiculares, redes viales más eficientes y nuevos y más seguros medios de transporte público (Morillo, 2020).

\subsection{Objetivo}

La presente investigación busca establecer una base informativa para el desarrollo de un modelo de evaluación y optimización de la movilidad urbana urbana de la ciudad de Tulcán - Provincia del Carchi, Ecuador, con base en criterios de sustentabilidad establecidos en los Objetivos de Desarrollo Sostenible de la Organización de las Naciones Unidas (2021) a través de una caracterización de la realidad socioeconómica y los parámetros técnicos que intervienen en el análisis, planificación y diseño de los sistemas de transporte. Número de viajes, centros de atracción y generación de viajes, partición modal, relación de uso entre modos motorizados y no motorizados, tiempos y costos de los viajes, externalidades del transporte como congestión y accidentabilidad, rutas de circulación vehicular, y propósitos de viajes son algunos de los principales aspectos que se consideran en el desarrollo del trabajo (de Dios Ortúzar, 2012).

\subsection{Justificación}

El desarrollo sustentable de las sociedades, requiere establecer planes de mejora continua de los mecanismos de protección ambiental, de las políticas de generación de un modelo de equidad social, y de los modelos de gestión y de crecimiento económico. Todas las actividades humanas, deben estar cimentadas sobre este triángulo de sostenibilidad que se constituya en la directriz estratégica para la gestión de los procesos de cualquier proyecto de desarrollo (Mura y Reyes, 2015). En sociedades pequeñas como la de la ciudad de Tulcán, no existe una documentación del estado de la movilidad urbana, donde se muestren indicadores que ayuden a las instituciones responsables de la planificación de las actividades urbanas y del uso del sistema de transporte, a establecer estrategias óptimas de desarrollo social, económico y tecnológico con un enfoque sostenible que consideren además, los intereses indiviuales y colectivos de las personas, y de los sectores públicos y privados (Alcántara, 2010).

Este problema requiere de un modelo de planificación soportado en soluciones tecnológicas para la gestión de la información generada en el funcionamiento diario del sistema de transporte y su interacción con las personas, que apunte a descubrir y a mejorar los aspectos críticos que influyen en el establecimiento de una movilidad urbana sustentable. Una vez que se disponga de una información estructurada, analizada y visualizada a través de cuadros de mando con tarjetas de indicadores, tablas y gráficos estadísticos, se podrá avanzar al diseño y a la implementación de sistemas de toma de decisiones para los usuarios y las entidades responsables de la 
gobernanza e institucionalidad del sistema urbano que integren mecanismos de simulación del comportamiento de las variables y las relaciones complejas propias de la naturaleza humana que entre ellas se presentan para evaluación previa del impacto de las implementaciones futuras (Hernández et al., 2012). Esta información será base además, para la creación de herramientas de control de la huella de carbono, algoritmos de optimización de operaciones, diseño y determinación de rutas con distintos niveles de integración modal, mecanismos de control y predicción de externalidades del transporte, y políticas de generación de nuevos sistemas de planificación sustentables para todas las actividades que se desarrollan en la movilidad urbana (QuinteroGonzález, 2017).

\section{Metodología}

El enfoque de la investigación fue de tipo cuantitativo, determinando los valores de un conjunto de indicadores establecidos como parámetros de evaluación de la sustentabilidad de la movilidad urbana de la ciudad de Tulcán detallados en trabajos como los de Alcántara (2010), Hernández et al.(2012), Quintero-González (2017) y de Dios Ortúzar (2012).

\subsection{Instrumentos}

Como se muestra en el trabajo de Obregón-Biosca y Betanzo-Quezada (2015), la recolección de los datos se hizo a través de una encuesta origen-destino, la misma que permite determinar la estructura de viajes entre las zonas de la ciudad de la cual se obtiene información relacionada con los aspectos principales de la movilidad urbana como la demanda de transporte, la partición modal, centros de atracción y generación de viajes, flujos vehiculares y propósitos de viajes, siendo este úlitmo, un indicador del comportamiento y de las necesidades laborales, comerciales, educacionales, de salud y recreativas de las personas que motivan el uso de los componentes del sistema de transporte y la movilidad urbana.

Para el análisis estadístico descriptivo se siguió una metodología como la presentada por Rivera (2019), utilizando herramientas open source para ciencia de datos e inteligencia de negocios, como MySQL y Power BI, que permitieron establecer el estado y las relaciones entre los parámetros de estudio del proyecto del cual se origina el presente artículo, para la dimensión de movilidad urbana. Los datos se obtuvieron de 598 encuestas que permiten establecer indicadores en forma de métricas y atributos calculados para parámetros de tiempos y costos asociados a la movilidad urbana, características del sistema de transporte y sus externalidades en la ciudad de Tulcán.

Estos criterios fueron estandarizados incialmente en un modelo relacional de datos ERD y, a partir de este, en un modelo de datos multidimensional tipo estrella no normalizado realizando un proceso OLAP (Online Analytical Processing) de Inteligencia de Negocios (Business Intelligence). Se realizó el proceso de extracción, transformación y carga de los datos (ETL) para finalmente presentar reportes de resultados de análisis multivariable estructurados en un cuadro de mando dinámico desarrollado utilizando el software libre POwer BI y que se está alimentado desde la base de datos de movilidad creada en MySQL Workbench (Quinatoa, 2018; Rivera, 2019).

El análisis de movilidad está delimitado en la zona geográfica comprendida en las parroquias Tulcán y González Suárez de la ciudad de Tulcán sobre una población de 86498 habitantes de acuerdo al último Censo 2010 de población y vivienda del Ecuador (Instituto Nacional de Estadística y Censo, 2021). 
Figura 1

Modelo de datos relacional y modelo de datos Multidimensional para OLAP - Base Movilidad Urbana - Tulcán

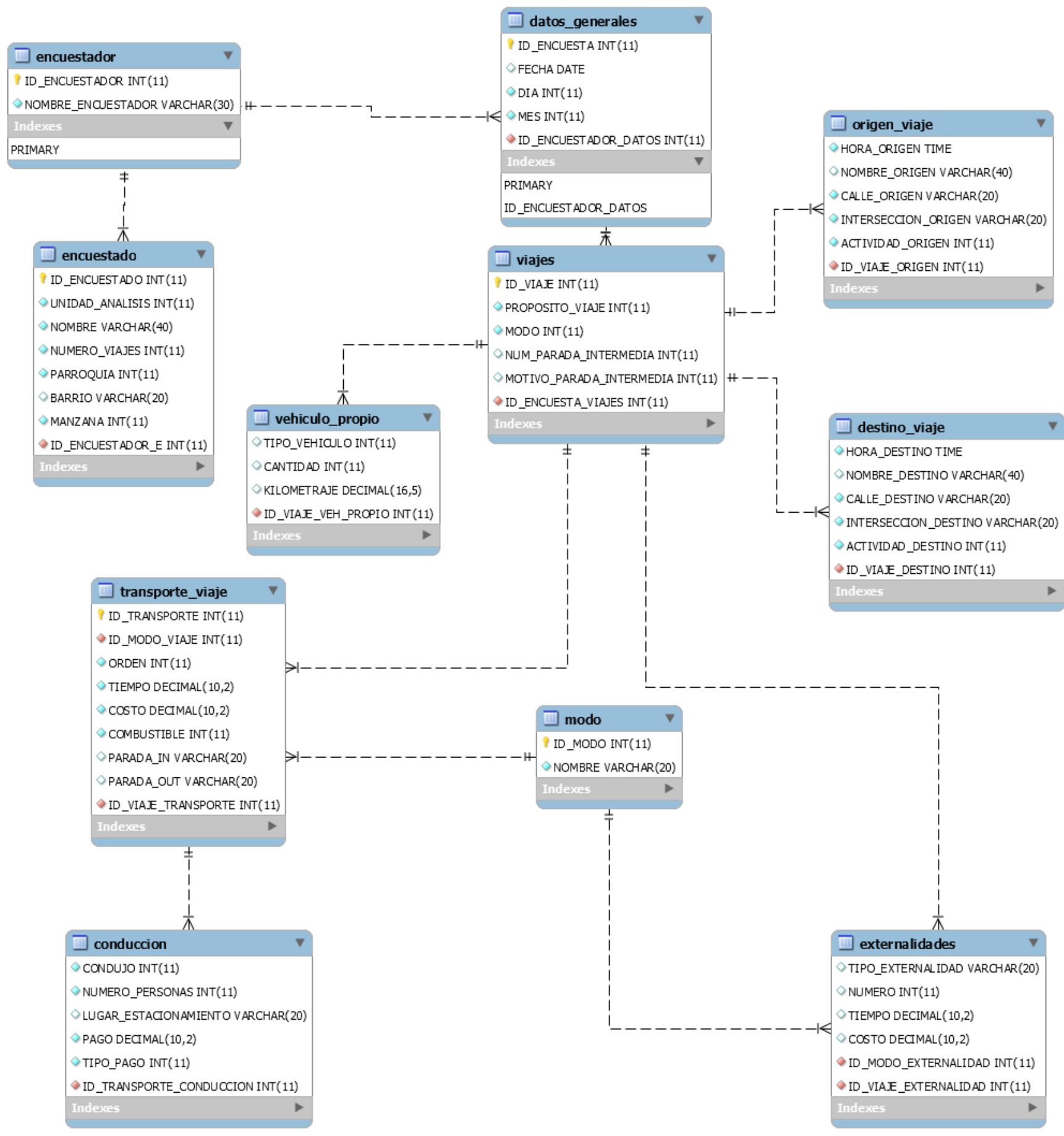




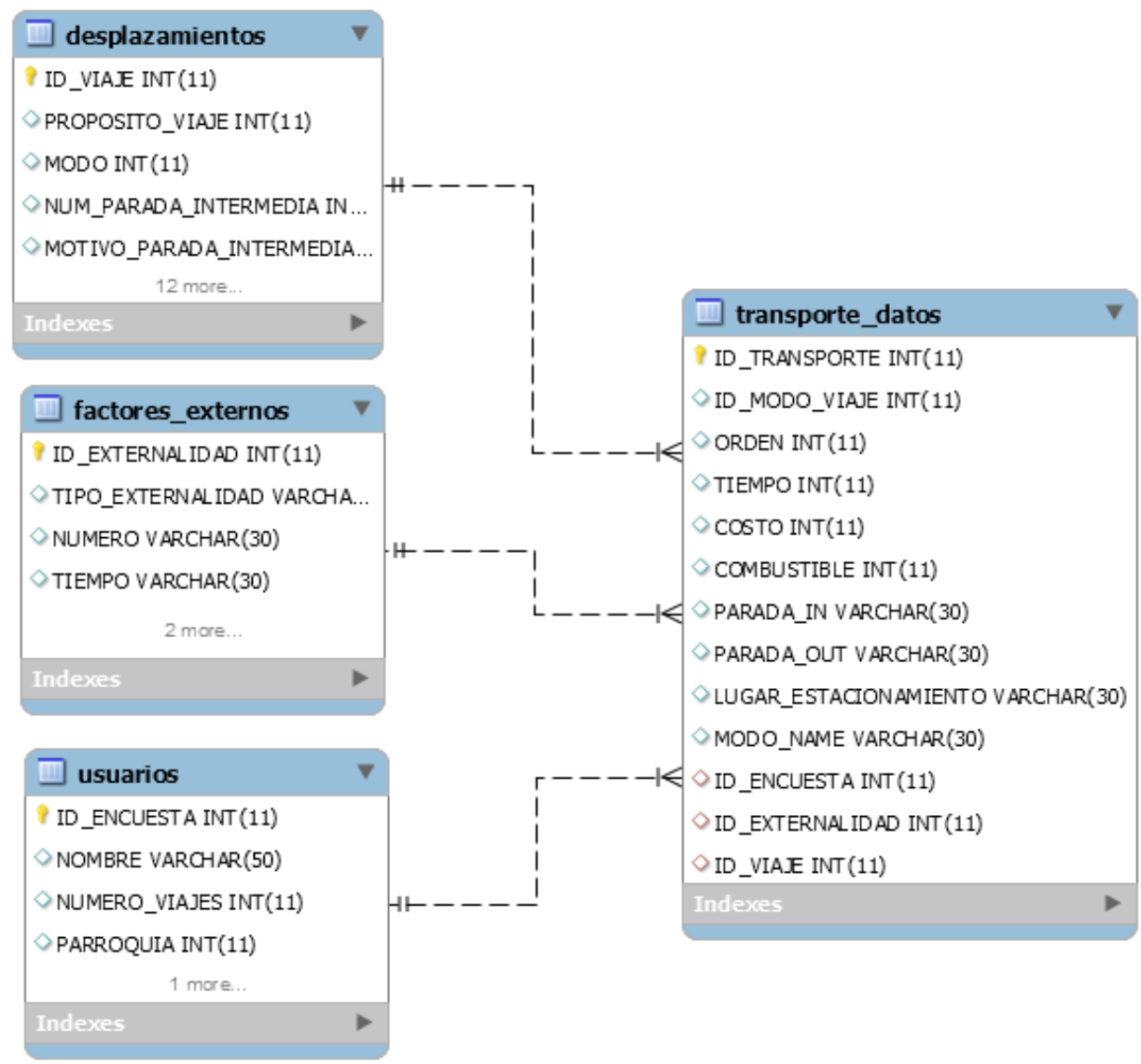

Fuente: Elaboración propia - MySQL

\section{Resultados}

Los resultados forman la base del modelo de evaluación de movilidad de acuerdo a los patrones de comportamiento de los parámetros identificados. En función de estos resultados, se determinan la sustentabilidad y los criterios de mejora de la movilidad urbana en la ciudad de Tulcán.

\subsection{Zonas de origen de viajes}

A nivel general, las zonas de origen de viajes están distribuidas a lo largo de la superficie geográfica de la ciudad de Tulcán, y están relacionadas principalmente con zonas de actividad comercial en más del $61 \%$, residenciales cerca del $24 \%$, y el $15 \%$ restante a las de tipo laboral y educativas. 
Figura 3

Zonas de origen de viajes por actividad

\section{ACTIVIDADES POR ZONAS DE ORIGEN}

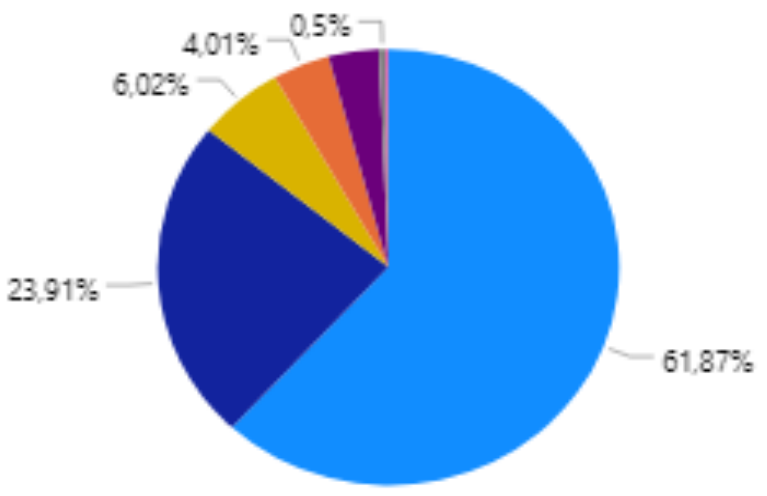

ACTIVIDAD

- Otro

- Residencial

- Comercio/Mercado

- Oficina

- Escuela

- Cutural/Recreacional

- Industria

Fuente: Elaboración propia - Power BI Desktop

\subsection{Zonas de destino de viajes}

Las zonas de destino de viajes se caracterizan en función del propósito de viaje. El $47 \%$ están relacionadas con actividades laborales, el $23 \%$ con zonas educativas y el $14 \%$ con zonas de actividad comercial.

Figura 4

Zonas de destino de viajes por actividad

\section{ACTIVIDADES POR ZONA DE DESTINO}

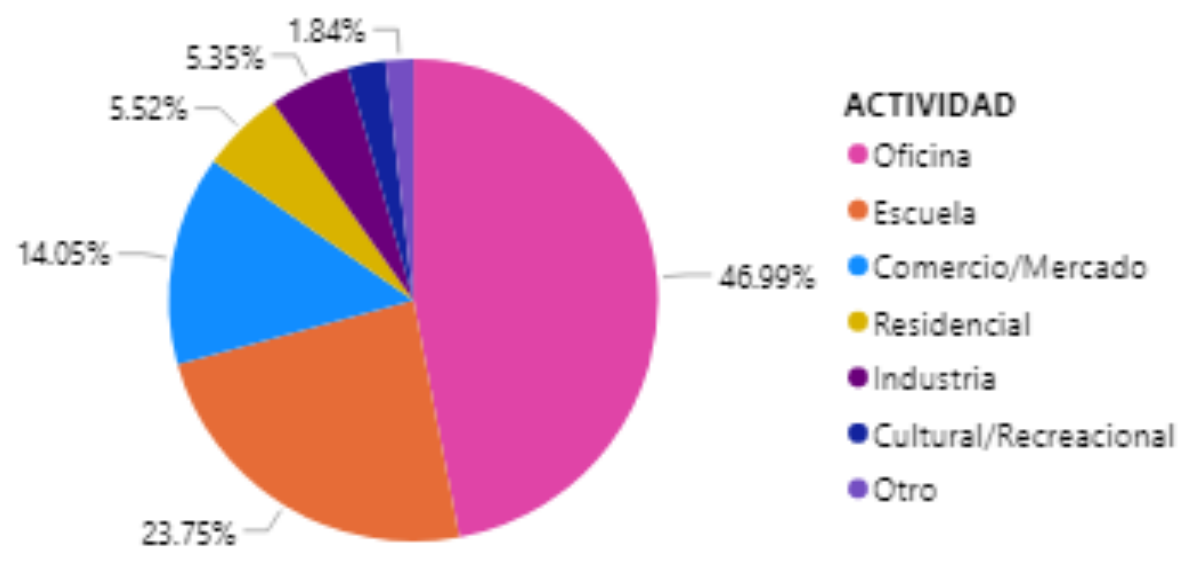

Fuente: Elaboración propia - Power BI Desktop

\subsection{Centros de atracción de viajes}

Los principales centros de atracción de viajes son zonas con actividades educativas, de trabajo y comerciales. La UPEC, una institución pública de educación superior que acoge a más de 3000 estudiantes y personal administrativo, aparece como el principal centro de atracción de viajes, seguida de importantes instituciones públicas como los gobiernos provincial y municipales, mercados e instituciones financieras, todas ubicadas en el centro de la ciudad. Del total de destinos registrados, solo 25 de ellos concentran el $67,66 \%$ del total de viajes. 
Figura 5

Principales centros de atracción de viajes

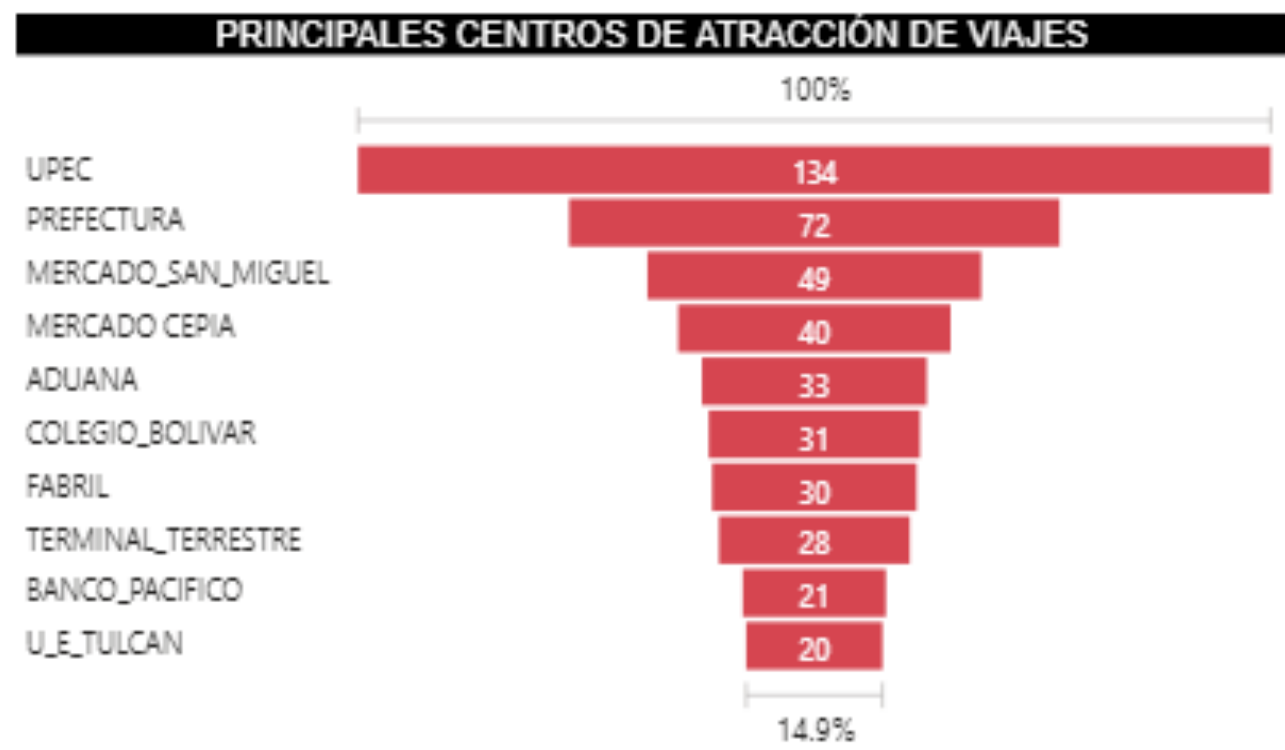

Fuente: Elaboración propia - Power BI Desktop

\subsection{Centros de generación de viajes}

El factor que más predomina para la generación de viajes es la distancia hasta las zonas céntricas de la ciudad donde se llevan a cabo las actividades comerciales y laborales. Se observa una alta generación de viajes desde el Barrio Olímpico y la Ciudadela 19 de noviembre. Otro factor que influye en la generación de viajes es la actividad comercial que se realiza en las zonas, como es el caso del Terminal Terrestre y el Mercado San Miguel, en los cuales existen altos niveles de oferta y demanda de transporte. Los resultados muestran que de los 107 orígenes identificados, solo 31 de ellos concentran aproximadamente el 74, 87\% del total de viajes realizados.

Figura 6

Principales centros de generación de viajes

\section{PRINCIPALES CENTROS DE GENERACIÓN DE VIAJES}

$100 \%$

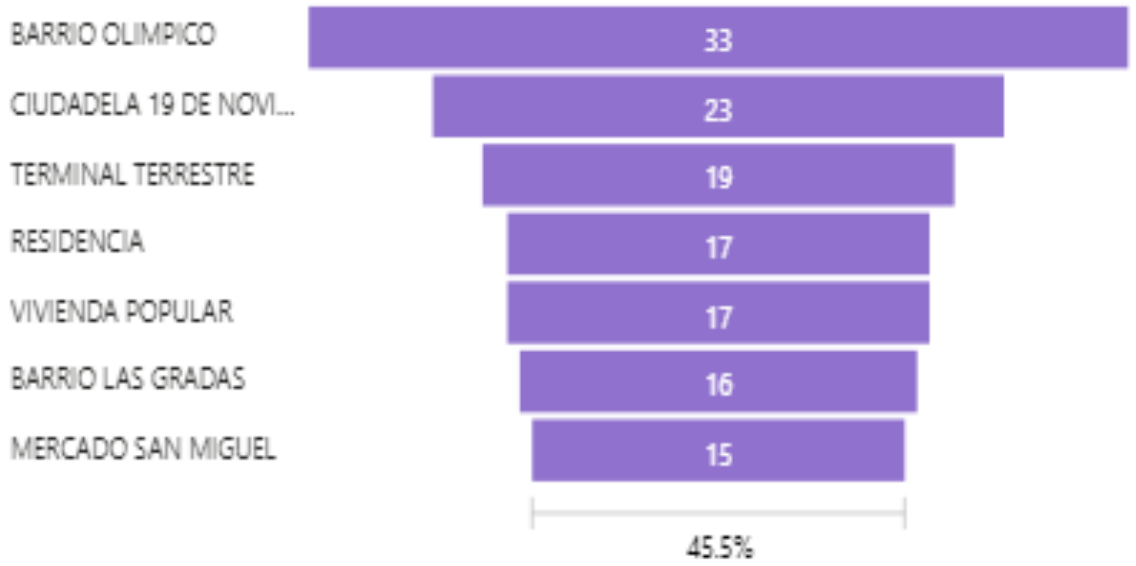

Fuente: Elaboración propia - Power BI Desktop 


\subsection{Partición Modal}

En la ciudad de Tulcán predomina el uso de la línea principal de transporte de bus público que circula por las vías centrales y que conecta de forma transveral los extremos de la ciudad. Esto puede ser debido a los bajos costos del servicio. Se observa también que prevalece el uso del servicio de taxis mediante aplicaciones móviles y call center sobre las solicitudes en sitio. Es importante también mencionar la notable participación de la caminata y la bicicleta en la realización de los viajes en varias zonas de la ciudad. Esto contribuye favorablemete a la sustentabilidad de la movilidad urbana en relación con la protección del medio ambiente.

Figura 7

Partición modal

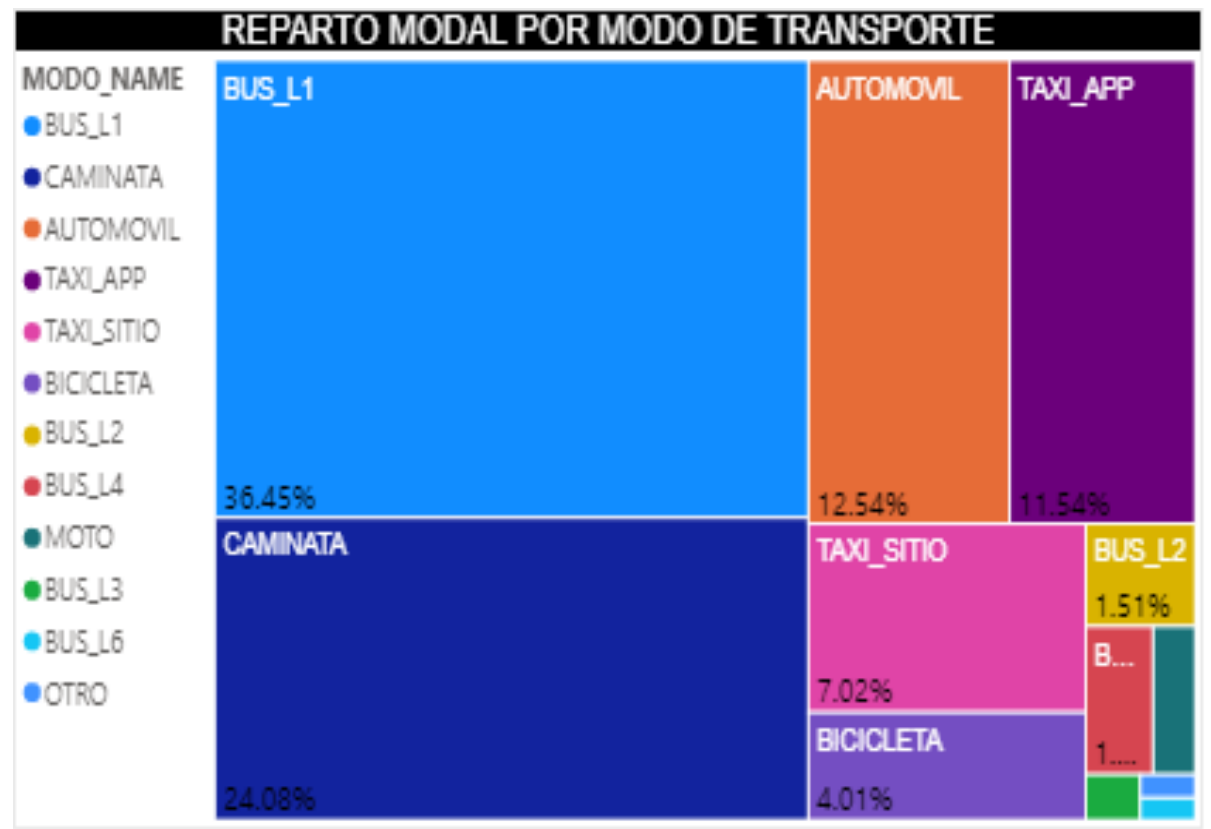

Fuente: Elaboración propia - Power BI Desktop

\subsection{Relación de uso entre transporte público y privado}

Teniendo en cuenta que el transporte público comprende el uso de buses y taxis y el transporte privado los demás modos de transporte, tales como caminata, bicicletas, automóviles y motos, se puede determinar que existe una relación de dos a uno entre el uso de transporte público y privado, con un $40 \%$ más de utilización.

Figura 8

Relación transporte público y privado

\section{RELACION DE USO ENTRE MODOS DE TRANSPORTE PUBLICO Y}

\section{PRIVADO}

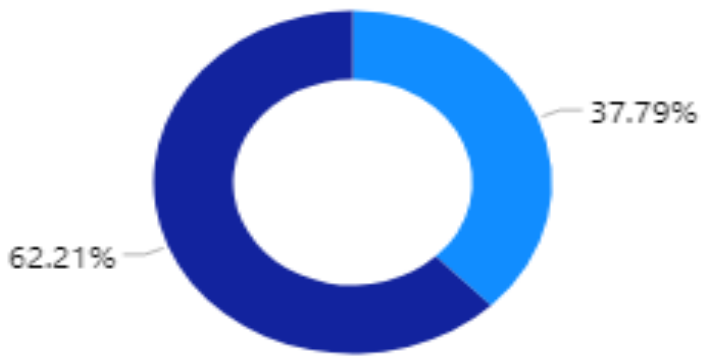

- TRANSPORTE_PRIVADO -TRANSPORTE PÚBLICO

Fuente: Elaboración propia - Power BI Desktop 


\subsection{Uso de transporte no motorizado}

Predomina el uso del transporte motorizado en relación con el transporte no motorizado, debido principalmente a las características de los grupos sociales como estudiantes y trabajadores que, en general, optan por un tipo de transporte que les permita satisfacer sus necesidades de manera inmediata, segura y a bajo costo. Sin embargo, el porcentaje de uso de transporte no motorizado es alto si se pone en contexto el tamaño de la ciudad, la cantidad de habitantes y su comparación con las principales ciudades del país, donde casi un $30 \%$ de los viajes se realizan de esta forma.

Figura 9

Relación transporte motorizado y no motorizado

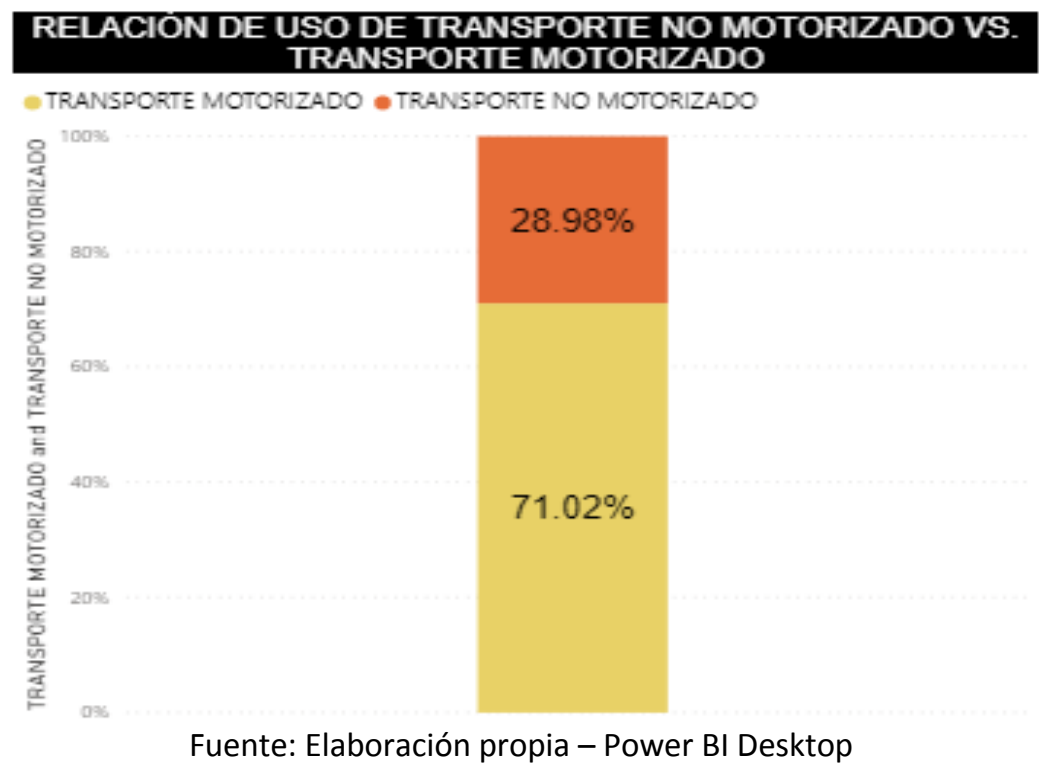

\subsection{Costos del transporte}

Los costos de transporte y de combustible se justifican debido a la reducida área geográfica de la ciudad de Tulcán que determina cortas distancias a recorrer entre los puntos de origen y destino de los viajes. Por tal motivo, los costos son relativamente bajos en comparación a otras ciudades como Ibarra y Quito, que tienen una población mayor y un tráfico vehicular más alto.

Figura 10

Costos diarios de transporte y combustible en viajes

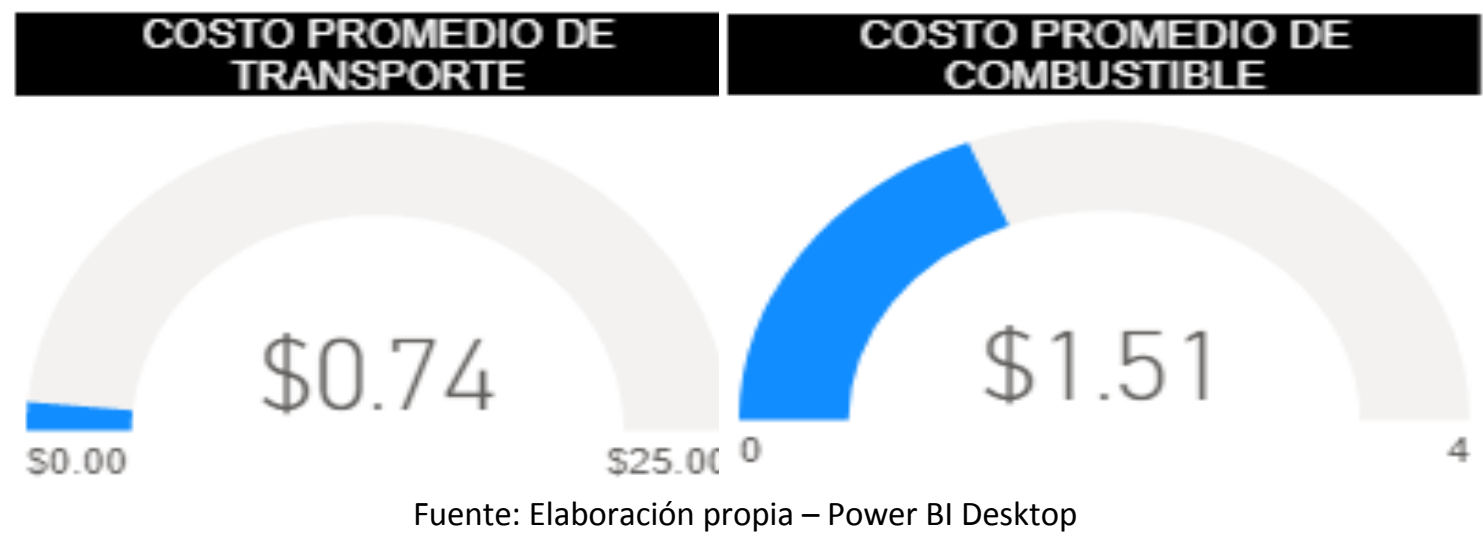

En cuanto a las diferentes líneas de bus público, los datos muestran que el costo del transporte para el modo Bus_L4 es el más elevado, lo que indica que las rutas que cubre son más largas, mientras que el Bus_L3 tiene 
la tarifa más baja porque cubre rutas más cortas o con varias paradas dentro de la urbe. Por otro lado, los buses Bus_L1 y Bus_L2 tienen tarifas similares. Sin embargo, el primero cubre rutas más demandadas, ya que el $62.44 \%$ de los encuestados eligieron este modo de transporte, además de que esta línea transita las principales calles de la ciudad. A diferencia de los anteriores modos, en el taxi el usuario debe cubrir el total del costo del servicio, puesto que no es subsidiado por el gobierno.Por ello, la tarifa de viaje duplica a la mayoría de las líneas de buses mencionadas.

Figura 11

Costos de transporte y tarifas

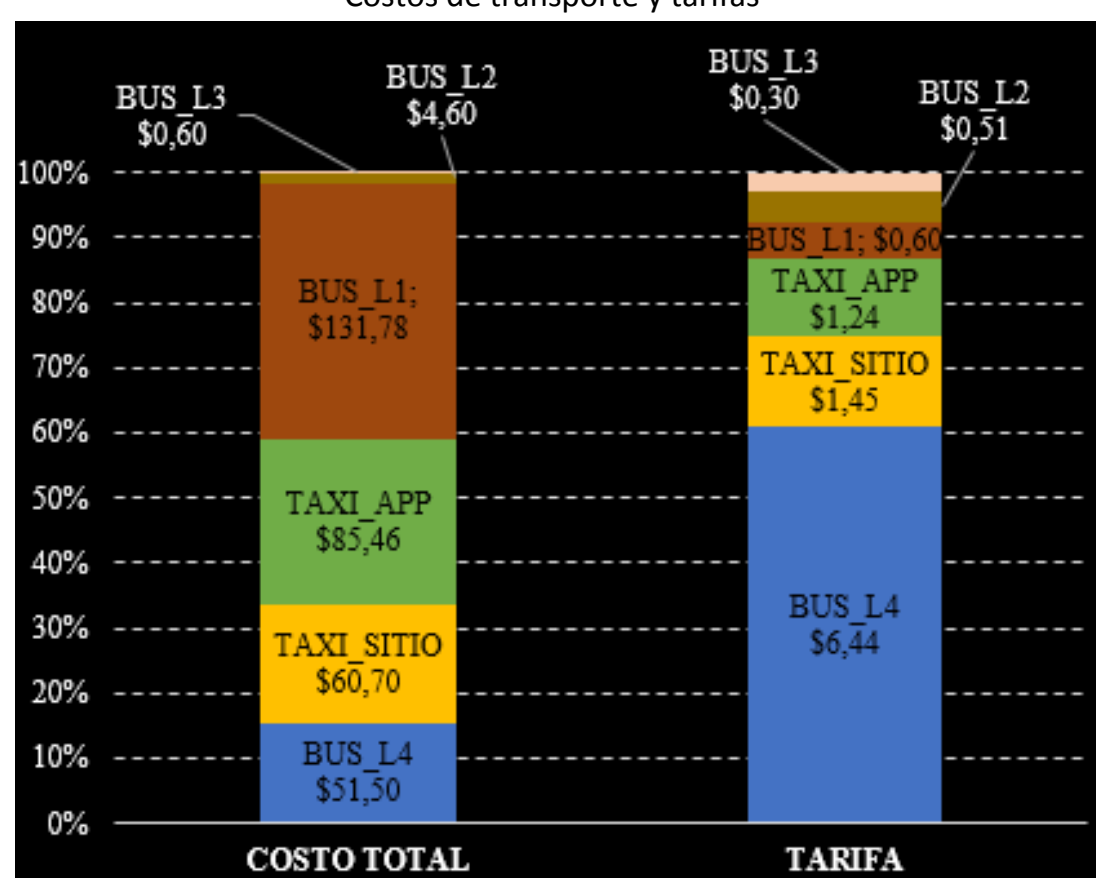

Fuente: Elaboración propia - Power BI Desktop

El costo del transporte privado resulta de la suma del costo del combustible y del estacionamiento por viaje, obteniéndose que el costo promedio del transporte para el automóvil es $0,47 \$$ mayor que el costo en moto, debido a que el número de viajes en moto es 15 veces menor al registrado en automóvil.

Figura 12

Costos de transporte y tarifas

\begin{tabular}{l|r|r|r|l|}
\hline MODO & $\begin{array}{l}\text { COMPUSTIBLE } \\
(\$)\end{array}$ & $\begin{array}{l}\text { ESTCIONAMIENIO } \\
(\$)\end{array}$ & $\begin{array}{l}\text { No. } \\
\text { VIAES }\end{array}$ & $\begin{array}{l}\text { COSTO } \\
\text { PROMEDIO } \\
\text { POR YIAUE }\end{array}$ \\
\hline AUTOMONL & 119 & 14,45 & 75 & 1,58 \\
MOTO & 6 & 0,30 & 5 & 1,11 \\
\hline Total & 124 & 14,75 & 80 & 1,55
\end{tabular}

Fuente: Elaboración propia - Power BI Desktop

\subsection{Propósitos de viaje}

Los principales propósitos de viajes están enfocados en satisfacer las necesidades básicas fundamentales de los habitantes: trabajo, médicina y educación, que tienen como finalidad conseguir estabilidad económica en los hogares y mejorar la calidad de la vida y el nivel de educación de la población. 
Figura 13

Principales propósitos de viajes

PRINCIPALES PROPOSITOS DE VIAJE

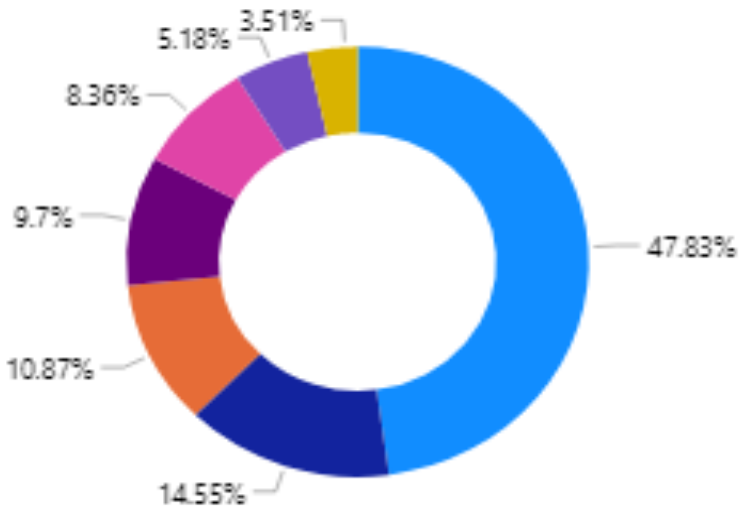

PROPOSITO

- trabajar

- IR AL MEDICO

eESTUdIAR

- OTRO

- IR DE COMPRAS

- llevar o recoger a ..-

-SOCIAL DEPORTES, RE.

Fuente: Elaboración propia - Power BI Desktop

\subsection{Principales rutas de viaje}

Considerando los propósitos de viaje mencionados, cuyas zonas de destino están ubicadas en el centro y sur de la ciudad, las rutas más frecuentes de los viajes de los habitantes circulan las calles principales de la ciudad de Tulcán como la calle Bolívar, calle Sucre, calle 10 de Agosto, Av. Veintimilla, Av. San Francisco, Av. Universitaria y las calles secundarias Brasil, Guatemala e Isla Santiago.

Figura 14

Principales rutas por propósito de viaje

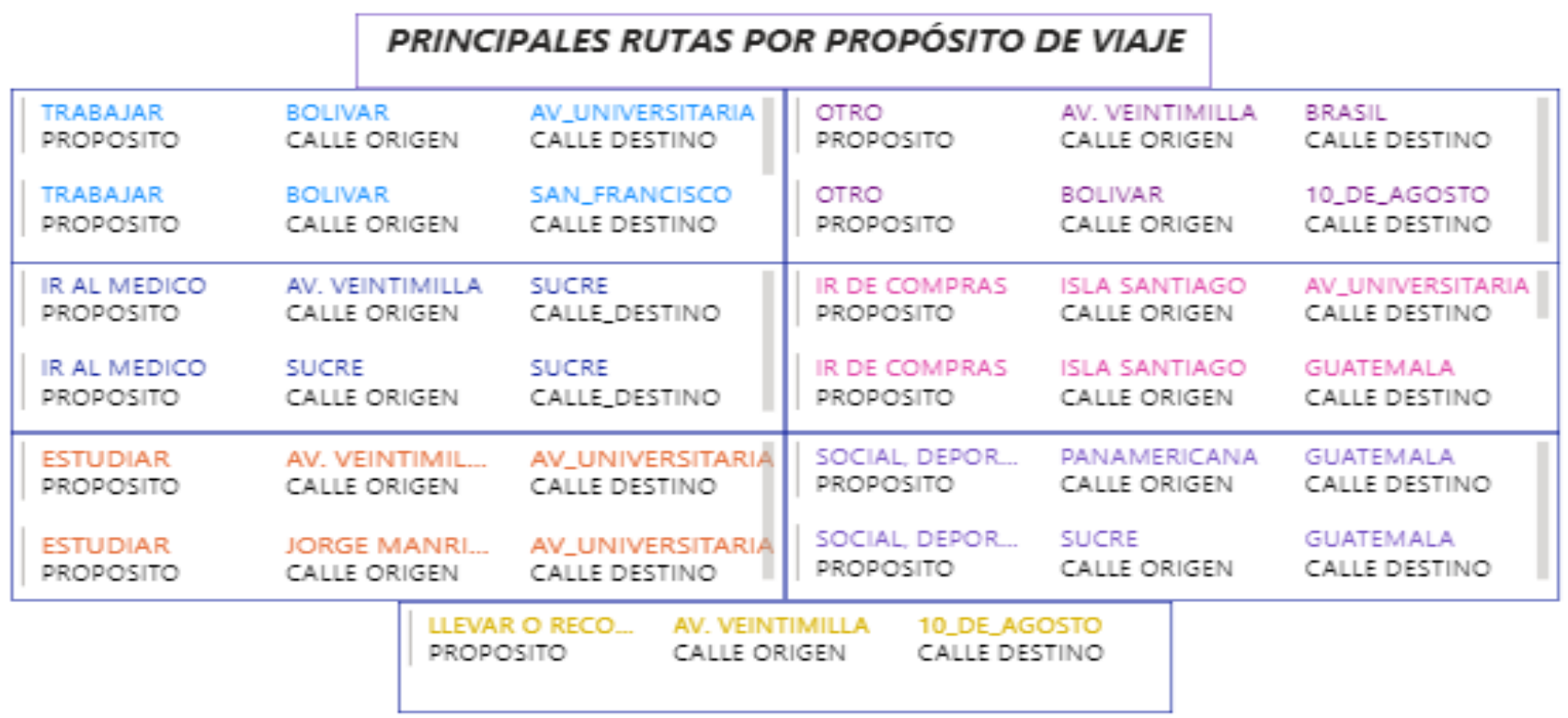

Fuente: Elaboración propia - Power BI Desktop

\subsection{Composición de los viajes}

Hace referencia al número de personas que, en el total de viajes del periodo de estudio, hacen uso de los diferentes modos de transporte. Se observa que predominan la demanda del bus con 273 personas, la caminata con 148 personas y el uso del automóvil con 48 personas. 
Figura 15

Composición de los viajes

\section{COMPOSICION DE VIAJES}

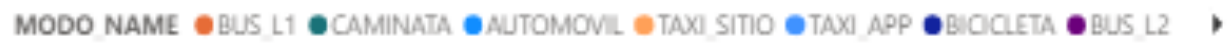

300

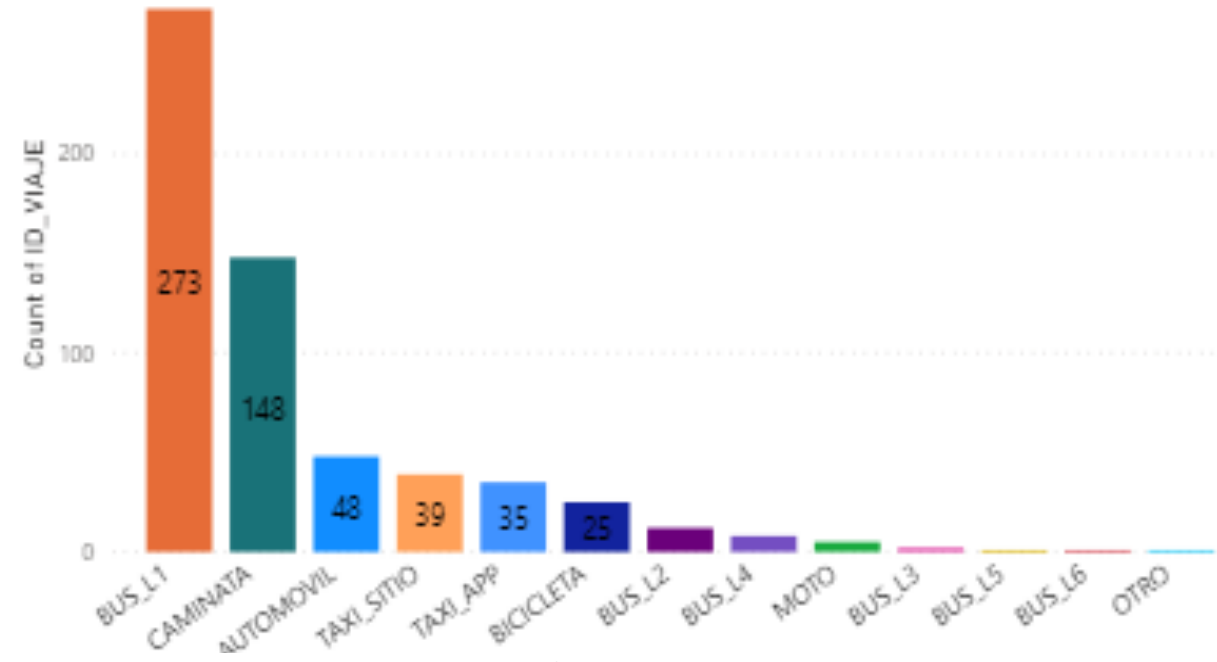

Fuente: Elaboración propia - Power BI Desktop

\subsection{Nivel de integración modal por viaje}

Los viajes para las principales rutas identificadas de acuerdo a la frecuencia de su uso están compuestos de un modo, como en las rutas Colegio Bolívar - UPEC, Barrio San Francisco - Mercado CEPIA, Parque Artesanal - UPEC y Terminal - Aduana, y hasta tres y cuatro modos en las rutas Estadio Olímpico - UPEC, Terminal UPEC, la Laguna - UPEC y San Vicente - UPEC. A nivel general, en la mayoría de las rutas existe una participación del modo Bus_L1, seguido de recorridos en tramos de las rutas caminando. Otras rutas de un nivel de integración se realizan con los modos Taxi-sitio, Bus_L2, Bus_L4 y bicicleta.

Figura 16

Nivel de integración modal por viaje

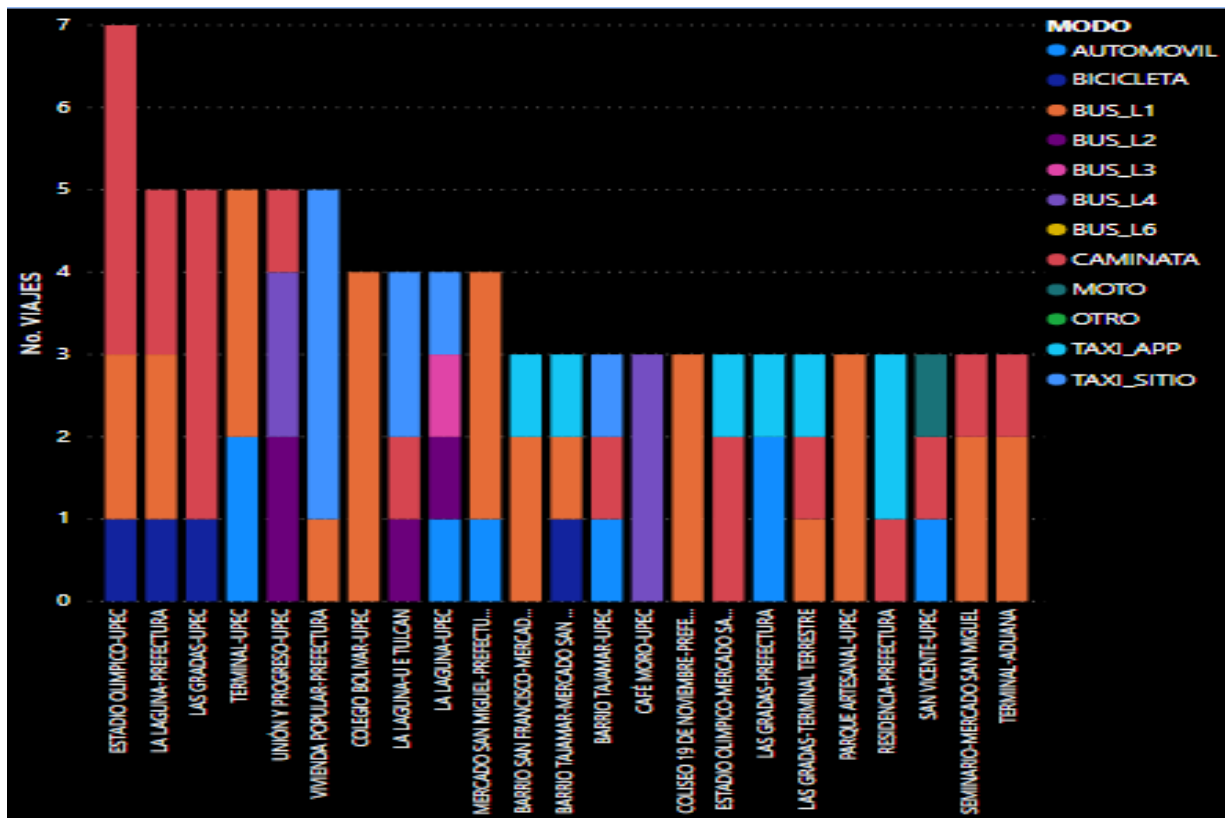

Fuente: Elaboración propia - Power BI Desktop 


\subsection{Zonas de estacionamiento y su incidencia en las externalidades del sistema de transporte}

Del estudio se observa que las zonas de estacionamiento tienen impacto en las externalidades del transporte, debido a que durante el periodo de análisis se registró que todos los choques estuvieron relacionados con el estacionamiento en la vía pública y los desperfectos mecánicos en los estacionamientos en zonas azules.

Figura 17

Zonas de estacionamiento e incidencia en externalidades

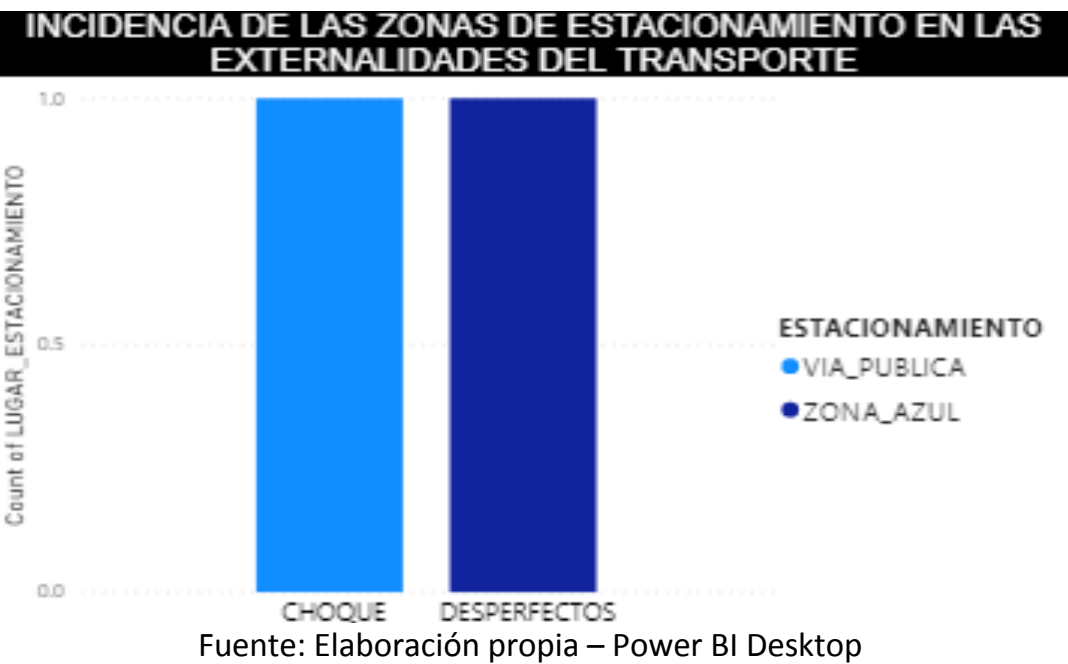

\subsection{Externalidades en viajes}

Tanto los desperfectos mecánicos como la accidentabilidad están asociados a la falta de infraestructura que sea capaz de solventar altos niveles de tráfico vehicular, además de fallas asociadas al factor humano por la falta de capacitación en materia de seguridad vial, así como la falta de iluminación y señalética que sean capaces de minimizar los índices de accidentabilidad. La incidencia en las externalidades es baja tomando en cuenta la cantidad de datos recolectados (Instituto Mexicano del transporte, 2005). La mayor cantidad de externalidades hace referencia a desperfectos mecánicos generados en el momento de estacionar o retirar los vehículos de los estacionamientos. Sin embargo, los choques y la colisión son casi inexistentes para los viajes registrados.

Figura 18

Externalidades durante viajes por horas

\section{TIPOS DE EXTERNALIDADES POR HORA}

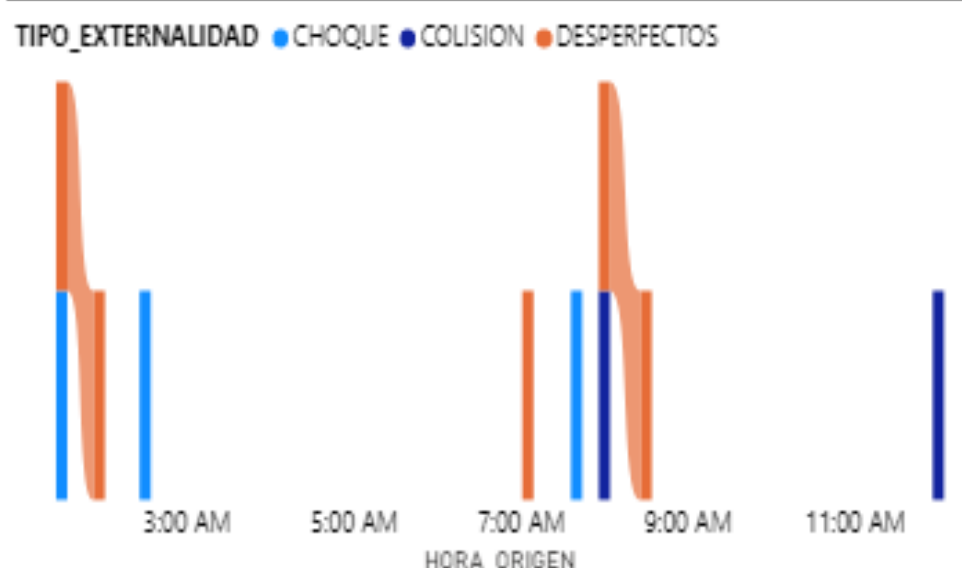

Fuente: Elaboración propia - Power BI Desktop 


\subsection{Congestión y flujos vehiculares}

La congestión y los flujos vehiculares son factores que están directamente relacionados con las actividades diarias de las personas. Se observa que los niveles más altos de tráfico vehicular y movilidad se dan en horas de la mañana, entre las 7:00 am y 10:00 am, periodo en el cual se genera la mayor cantidad de viajes porque se inician las actividades.

Figura 19

Congestión y flujos vehiculares

\section{FLUJO VEHICULAR}

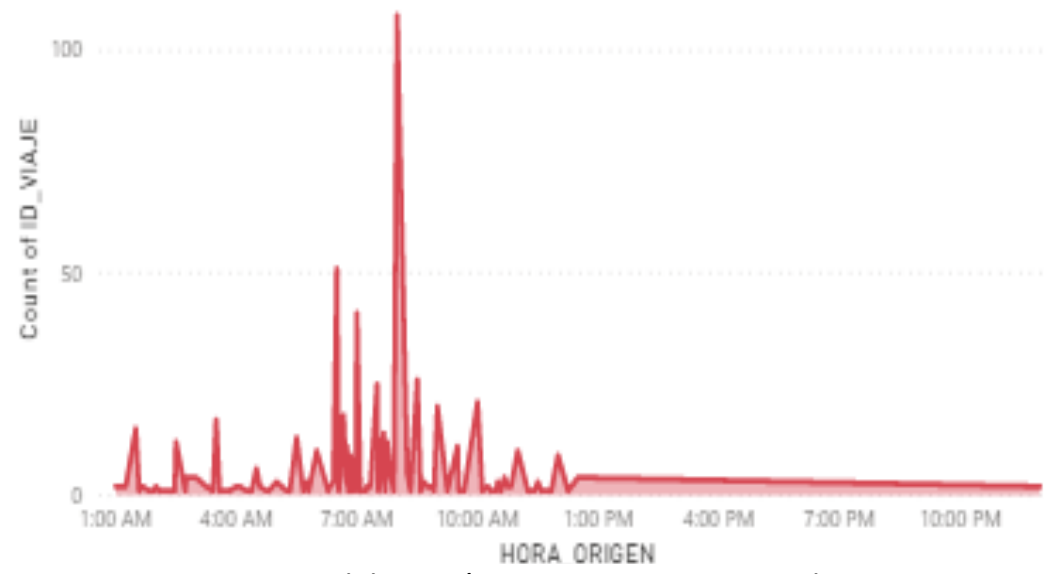

Fuente: Elaboración propia - Power BI Desktop

\subsection{Partición modal por frecuencia de destino}

De los resultados se obtuvo que la mayor cantidad de personas se movilizan hacia la UPEC, siendo el lugar con más atracción y generación de viajes. Los modos de transporte más utilizados para dirigirse a este lugar son el bus (BUS_L1) y la caminata, debido a que la mayoría de usuarios de esta ruta de viajes son estudiantes. Es importante este dato porque denota la importancia del transporte público y los medios no motorizados en la realización de los viajes a los destinos más frecuentes aunque, de forma general, el alto uso de estos modos de transporte es visible independientemente del destino de viaje.

Figura 20

Partición modal por destino de viaje

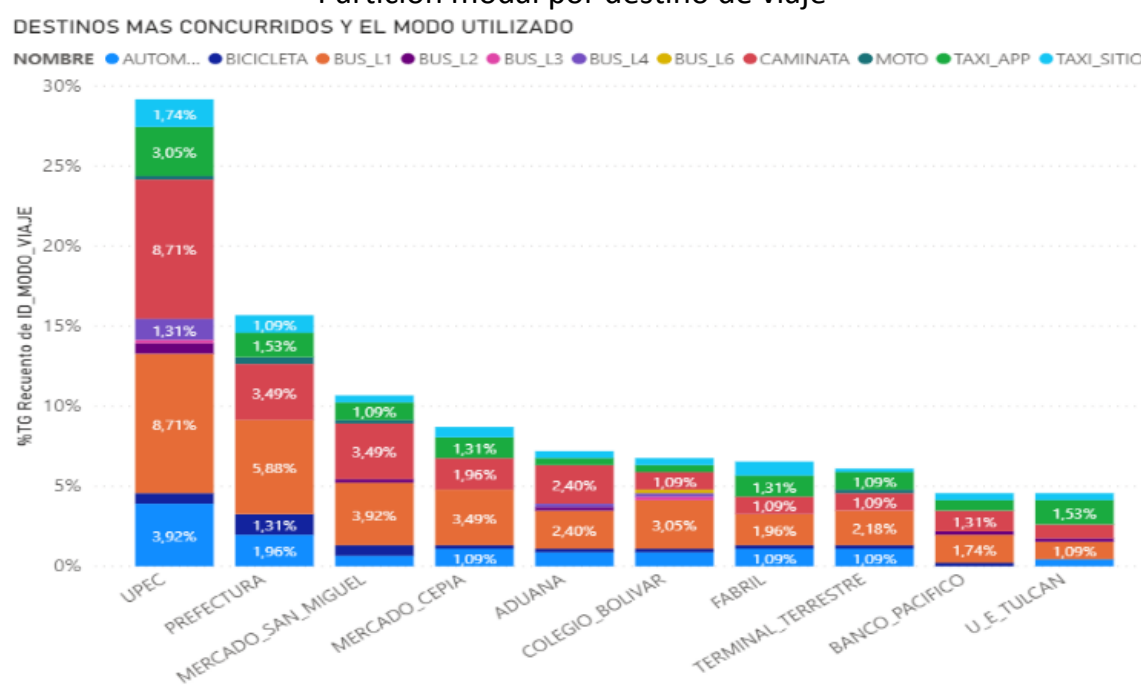

Fuente: Elaboración propia - Power BI Desktop 


\subsection{Tiempos de viaje por modo}

Los tiempos de viaje para los distintos modos de transporte varían porque dependen de muchos factores como horario, congestión y externalidades. Por ejemplo, los viajes en el transporte de bus público (Bus_l1) toman en promedio 35 minutos hasta la UPEC desde orígenes en los sectores norte y sur de la ciudad, mientras que quienes utilizan moto tardan en promedio 4 minutos por las características propias de este modo además de que circulan por vías menos congestionadas que las que utlizan los buses públicos (Av. Coral, Calle Bolívar, Av. Veintimilla y Calle Rafael Arellano). Sin embargo, independientemente del tiempo de viaje, los usuarios prefieren, en su mayoría, usar el bus público o caminar.

Figura 21

Tiempo de viaje por modo

\begin{tabular}{|c|c|c|c|}
\hline NOMBRE & Promedio de TIEMPO_VIAJE & \%TG Recuento de REFERENCIA ORIGEN & PUNTO_REFERENCIA_DESTINO $\bullet$ UPEC $\bullet$ Promedio de TIEMPO_VIAJE \\
\hline BUS_L1 & 35,2 & $30,08 \%$ & \\
\hline CAMINATA & 13,2 & $30,08 \%$ & $\frac{\underline{\underline{m}}}{0}$ \\
\hline AUTOMOVIL & 12,8 & $13,53 \%$ & $\frac{4}{\mathrm{U}}$ \\
\hline TAXI_APP & 15,4 & $9,77 \%$ & 6 崖 2 \\
\hline TAXI_SITIO & 10,8 & $6,02 \%$ & \\
\hline BUS_L4 & 29,5 & $4,51 \%$ & \\
\hline BICICLETA & 11,3 & $2,26 \%$ & 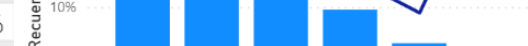 \\
\hline BUS_L2 & 17,3 & $2,26 \%$ & 党 \\
\hline BUS_L3 & 35,0 & $0,75 \%$ & \\
\hline МОТО & 4,0 & $0,75 \%$ & \\
\hline Total & 20,7 & $100,00 \%$ & NOMBRE \\
\hline
\end{tabular}

Fuente: Elaboración propia - Power BI Desktop

\subsection{Tiempos de viajes por ruta}

Las rutas El portal-Colegio Bolívar, Vivienda Popular-Mercado CEPIA, Vivienda Popular-TRANSBOLIVARIANA y Parque Artesanal-UPEC son las rutas que mayores tiempos de viaje registran, mientras que en tramos como la intersección Quito y Sucre hasta el terminal terrestre el tiempo es de solo 5 minutos. Estos tiempos de viaje se justifican por la distancia existente entre los extremos de la ruta.

Figura 22

Tiempos de viaje por ruta

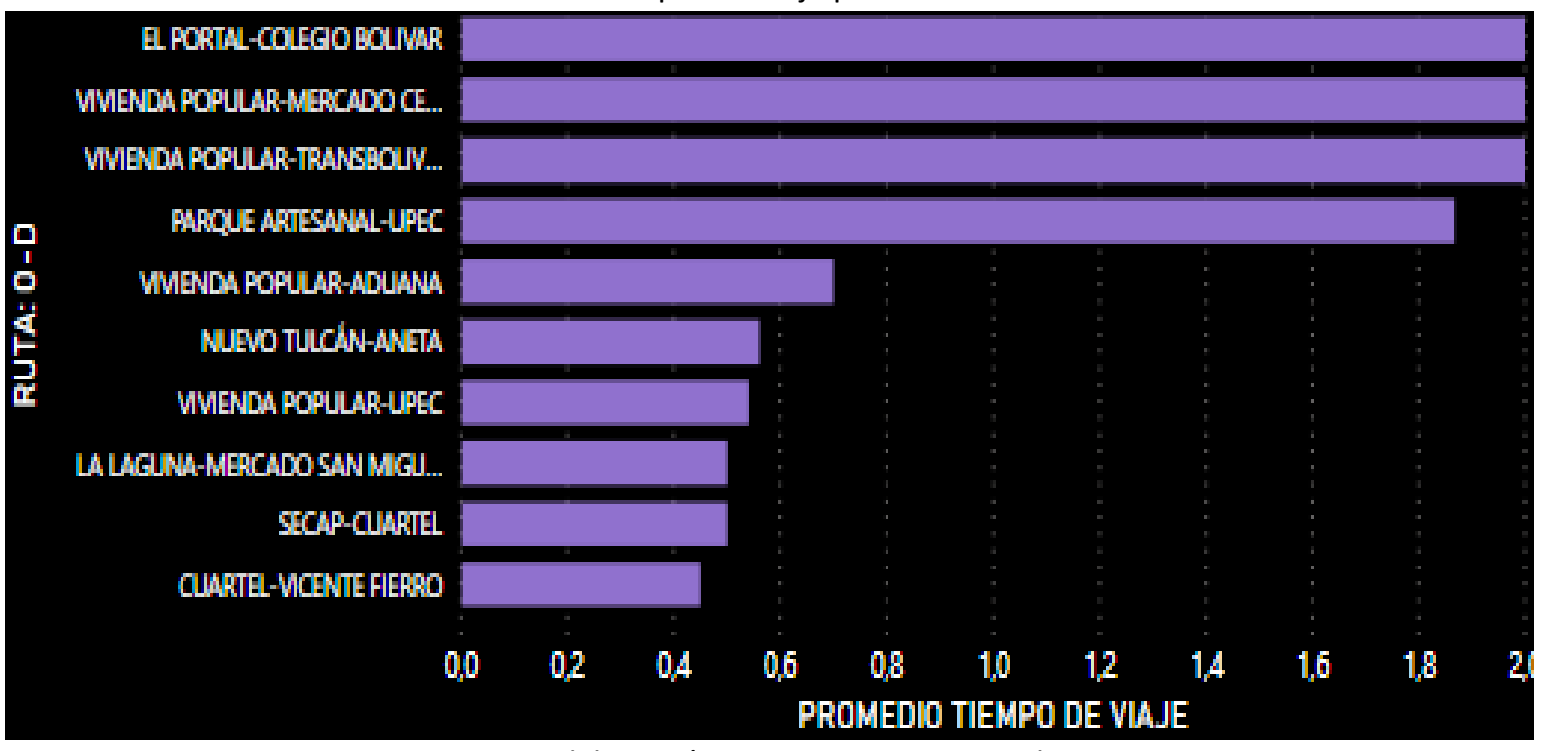

Fuente: Elaboración propia - Power BI Desktop 


\subsection{Externalidades de viaje por modo}

Sea cual sea el medio de transporte que utilicen los usuarios para trasladarse de un punto de origen a uno de destino, en algún momento han llegado a sufrir externalidades. Las más frecuentes son los choques y los desperfectos, en especial en los automóviles, pues este modo ha tenido al menos uno de cada tipo de externalidad. El bus público y taxis presentan únicamente un choque, cada uno. Los modos que menos externalidades sufren son la bicicleta y la caminata, el cual es un resultado importante en relación con la seguridad vial y peatonal para usuarios más vulnerables.

Figura 23

Externalidades por modo

EXTERNALIDADES QUE SUFREN LOS MODOS DE TRANSPORTE

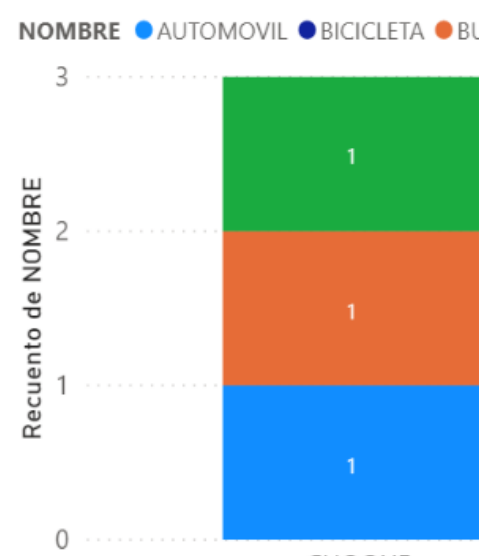

CHOQUE

- CAMINATA -TAXI_APP

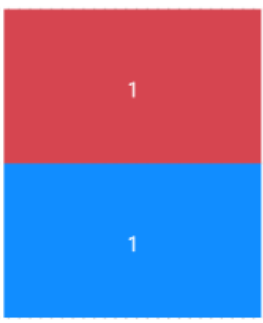

COLISION

TIPO_EXTERNALIDAD

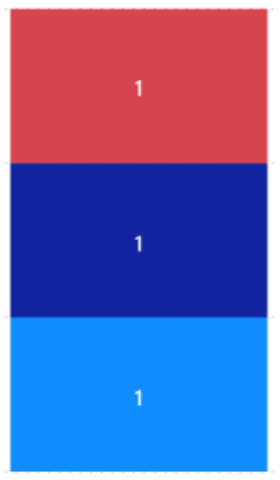

DESPERFECTOS

Fuente: Elaboración propia - Power BI Desktop

\subsection{Propósito de viaje por modo}

La actividad con mayor participación es la de ir a trabajar, con un total de 451 viajes y el modo con mayor aportación de viajes en esta actividad es el bus público, con un total de 356 viajes. Se observa que para cada actividad los modos más utilizados son el bus público, la caminata y el automóvil, en ese orden.

Figura 24

Propósito de viaje por modo

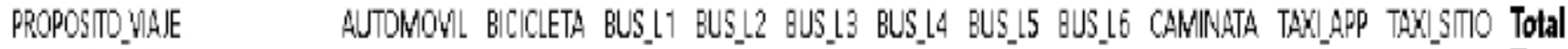

\begin{tabular}{|c|c|c|c|c|c|c|c|c|c|c|c|c|}
\hline TRABAAAR & 51 & & 114 & 27 & 72 & 106 & & 37 & 31 & 12 & 1 & 451 \\
\hline RAL MED|CO & 41 & 11 & 54 & 33 & & 3 & & 3 & 58 & & & 203 \\
\hline OTRO & 43 & & 49 & 3 & 8 & 9 & & & 53 & & & 165 \\
\hline LLEVARO RECOGER. A.ALGUIEN & & 10 & 30 & & 11 & 18 & 10 & & 13 & & & 100 \\
\hline ESTUDIAR & & & 33 & & 8 & 37 & & 13 & & & & 91 \\
\hline IR. DE COMPRAS & 1 & & 20 & 1 & & 13 & & 19 & 24 & 12 & & 90 \\
\hline SOCIAL, DEPORTES, RECREACIONN & 24 & & 3 & & & 18 & & 12 & 1 & & & 58 \\
\hline Total & 160 & 21 & 311 & 64 & 99 & 204 & 10 & 84 & 100 & 24 & & 1158 \\
\hline
\end{tabular}




\subsection{Costos por externalidad}

De entre los tipos de externalidades que se registran en los datos analizados, es la colisión la que más costos genera, pues el promedio de costo por instancia de colisión es de $\$ 50$. Los choques implican un costo promedio de $\$ 16$ por choque y los desperfectos mecánicos en viaje generan un promedio de de $\$ 13,2$ por desperfecto. Sin embargo, se recalca que el número de externalidades es relativamente bajo.

Figura 25

Costo por externalidad

\section{PROMEDIO DEL COSTO DE LAS EXTERNALIDADES}

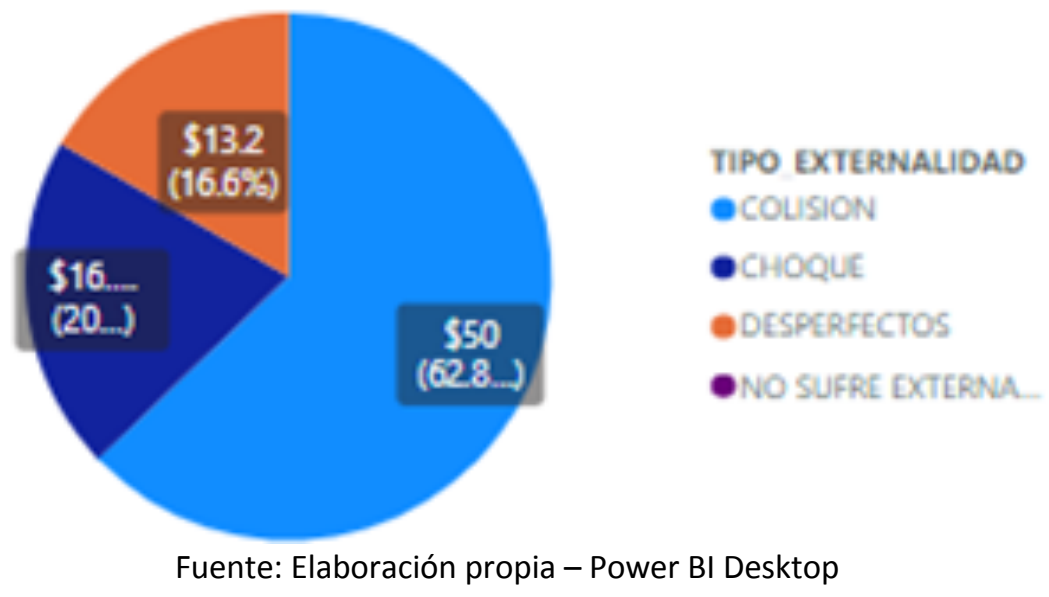

\subsection{Flujos de viajes por calle}

Se observa que las calles más transitadas son la Calle 10 de agosto y la Av. Universitaria. El modo de transporte más utilizado para llegar a estos dos lugares es el bus público, con un $37,44 \%$ de los viajes por estas calles, lo que es coherente con los resultados de los puntos anteriores, además de que estas dos calles son vías de acceso y salida hacia y desde los principales centros de atracción y generación de viajes: la UPEC y el parque central de la ciudad.

Figura 26

Flujos de viajes por calles

\begin{tabular}{|c|c|c|c|c|c|c|c|c|c|c|c|c|}
\hline CALLE_DESTINO & AUTOMOVIL & BICICLETA & BUS_L1 & BUS_L2 & BUS_L3 & BUS_L4 & BUS_L5 & BUS_L6 & CAMINATA & TAXI_APP & TAXI_SITIO & Total \\
\hline NO DEFINIDO & $4,93 \%$ & $0,49 \%$ & $10,84 \%$ & $2,96 \%$ & $2,96 \%$ & $1,48 \%$ & & $1,48 \%$ & $7,39 \%$ & $0,99 \%$ & & $33,50 \%$ \\
\hline 10 DE AGOSTO & $1,97 \%$ & & $2,96 \%$ & $2,96 \%$ & $1,97 \%$ & $0,49 \%$ & & $1,48 \%$ & $0,99 \%$ & & & $12,81 \%$ \\
\hline AV UNIVERSITARIA & $0,99 \%$ & & $5,91 \%$ & $0,49 \%$ & & $3,45 \%$ & $0,49 \%$ & $0,99 \%$ & $0,49 \%$ & & & $12,81 \%$ \\
\hline SUCRE & & $0,49 \%$ & $3,45 \%$ & $1,48 \%$ & & $0,49 \%$ & & $0,99 \%$ & & & & $6,90 \%$ \\
\hline ARGENTINA & & & $2,46 \%$ & & $0,49 \%$ & $1,48 \%$ & & $0,49 \%$ & & & & $4,93 \%$ \\
\hline GUATEMALA & & & $2,96 \%$ & & & $1,48 \%$ & & $0,49 \%$ & & & & $4,93 \%$ \\
\hline SAN FRANCISCO & $0,49 \%$ & & $1,48 \%$ & & & $0,99 \%$ & & $1,48 \%$ & $0,49 \%$ & & & $4,93 \%$ \\
\hline BOLIVAR & $0,99 \%$ & & $1,48 \%$ & $0,99 \%$ & & & & $0,49 \%$ & & & $0,49 \%$ & $4,43 \%$ \\
\hline JULIO ROBLES & & & $0,49 \%$ & $0,49 \%$ & & $0,99 \%$ & & $0,49 \%$ & & & & $2,46 \%$ \\
\hline RAFAEL ARELLANO & & & $0,99 \%$ & $0,99 \%$ & & $0,49 \%$ & & & & & & $2,46 \%$ \\
\hline VENTIMMILLA & & & $1,48 \%$ & & & $0,99 \%$ & & & & & & $2,46 \%$ \\
\hline TRONCAL SIERRA & & & $0,99 \%$ & $0,49 \%$ & & $0,49 \%$ & & & & & & $1,97 \%$ \\
\hline MANABI & & & $0,99 \%$ & & & $0,49 \%$ & & & & & & $1,48 \%$ \\
\hline PANAMA & & & & $0,49 \%$ & $0,49 \%$ & $0,49 \%$ & & & & & & $1.48 \%$ \\
\hline BRASIL & & & $0,49 \%$ & & & $0,49 \%$ & & & & & & $0,99 \%$ \\
\hline 8 DE DICIEMBRE & & & & & $0,49 \%$ & & & & & & & $0.49 \%$ \\
\hline CHIMBORAZO & $0,49 \%$ & & & & & & & & & & & $0.49 \%$ \\
\hline CORAL & & & $0,49 \%$ & & & & & & & & & $0,49 \%$ \\
\hline Total & $9.85 \%$ & $\begin{array}{r}0.99 \% \\
F\end{array}$ & $\begin{array}{l}3744 \% \\
\text { uente: } E\end{array}$ & $\begin{array}{l}11.33 \% \\
\text { laborac }\end{array}$ & $\begin{array}{l}6.40 \% \\
\text { ión pro }\end{array}$ & $\begin{array}{c}1429 \% \\
\text { pia - Pov }\end{array}$ & $\begin{array}{c}0.49 \% \\
\text { wer BI D }\end{array}$ & $\begin{array}{c}8.37 \% \\
\text { Desktop }\end{array}$ & $936 \%$ & $0.99 \%$ & $0.49 \%$ & $10000 \%$ \\
\hline
\end{tabular}




\subsection{Uso de bicicleta por actividad}

Los viajes en bicicleta durante el periodo analizado en la ciudad de Tulcán solo corresponden al 4,18\% del total de viajes, a pesar de que esta actividad es tendencia en ciudades del primer mundo. El principal motivo del uso de la bicicleta en la ciudad de Tulcán es el traslado al trabajo, lo cual difiere del informe realizado por el Gobierno Autónomo Descentralizado Municipal de Tulcán (2020) en un proyecto de ciclovías en el que menciona que "la bicicleta es usada como recreación o deporte principalmente y no para transportarse" (p. 6). El sector de origen de estos viajes es principalmente el Estadio Olímpico, mientras que los principales destinos son la Prefectura, el Mercado San Miguel, la UPEC y la empresa TRANSBOLIVARIANA, lo que se explica por ser zonas donde está más desarrollada la actividad comercial y se localizan los servicios, instituciones y las principales fuentes de empleo de la ciudad.

Figura 27

Viajes en bicicleta por zona de origen y destino

\begin{tabular}{|c|c|c|c|c|c|}
\hline ORIGEN & No. VAJES & \%PARTC. & DESTINO & No. VIAUES & \%PARTC. \\
\hline ESTADIO OLIMPICO & 6 & $25,00 \%$ & PREFECTURA & 6 & $26,09 \%$ \\
\hline NULL & 4 & $16.67 \%$ & MERCADO SAN & 3 & $13,04 \%$ \\
\hline BARRIO $\triangle$ DE FEBREO & 1 & $4,17 \%$ & MIGUEL & & \\
\hline BARRIO TAJAMAR & 1 & $4,17 \%$ & UPEC & 3 & $13,04 \%$ \\
\hline BELLAVISTA & 1 & $4,17 \%$ & TRANSBOLIVARIANA & 2 & $8,70 \%$ \\
\hline $\begin{array}{l}\text { CIUDADELA } 13 \text { DE } \\
\text { DICIEMBRE }\end{array}$ & 1 & $4,17 \%$ & ADUANA & 1 & $4,35 \%$ \\
\hline CIUDADELA 19 DE & 1 & $4,17 \%$ & AKI & 1 & $4,35 \%$ \\
\hline NOVIEMBRE & & & ANETA & 1 & $4,35 \%$ \\
\hline ESCUELA ALEJANDRO & 1 & $4,17 \%$ & BANCO PACIFICO & 1 & $4,35 \%$ \\
\hline GRAL ELOY ALFARO & 1 & $4,17 \%$ & COLEGIO BOLIVAR & 1 & $4,35 \%$ \\
\hline $\begin{array}{l}\text { LA LAGUNA } \\
\text { LAS GRADAS }\end{array}$ & 1 & $\begin{array}{l}4,17 \% \\
4,17 \%\end{array}$ & COMERCIAL & 1 & $4,35 \%$ \\
\hline MERCADO CENTRAL & 1 & $4,17 \%$ & POPULAR & & \\
\hline PADRE PONCE & 1 & $4,17 \%$ & FABRIL & 1 & $4,35 \%$ \\
\hline RAFAEL ARELLANO & 1 & $4,17 \%$ & MERCADO CEPIA & 1 & $4,35 \%$ \\
\hline SAN VICENTE & 1 & $4,17 \%$ & TERMINAL & 1 & $4,35 \%$ \\
\hline VIVIENDA POPULAR & 1 & $4,17 \%$ & TERRESTRE & & \\
\hline Total & 24 & $100,00 \%$ & Total & 23 & $100,00 \%$ \\
\hline
\end{tabular}

Fuente: Elaboración propia - Power BI Desktop

Figura 28

Propósito de viajes en bicicleta
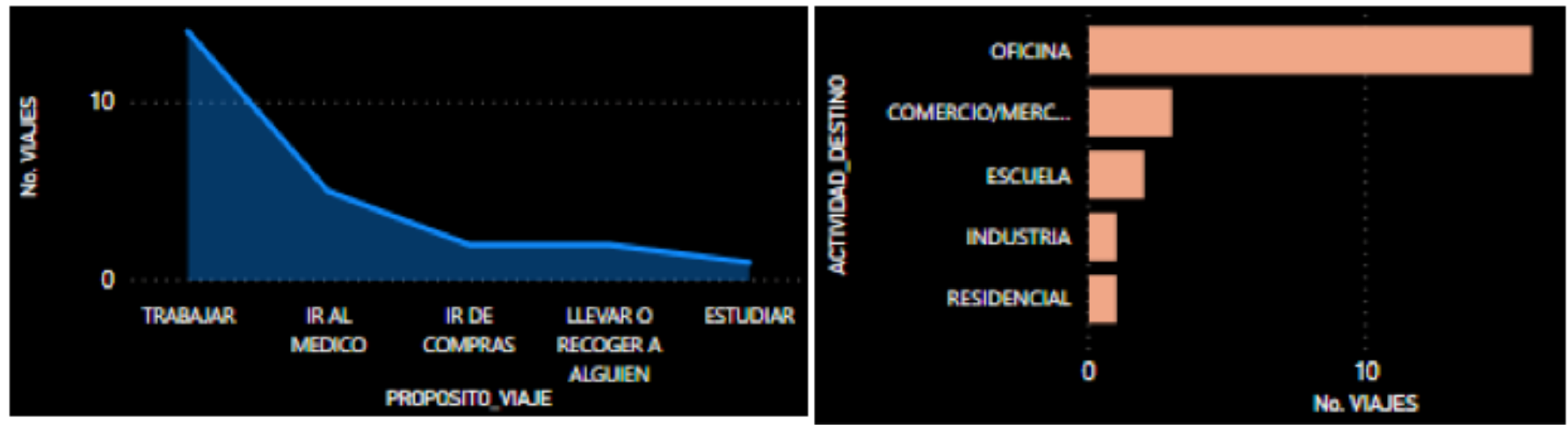

Fuente: Elaboración propia - Power BI Desktop 


\subsection{Uso de bicicleta por hora}

De acuerdo con los datos, la mayor cantidad de viajes se dan en horas de la mañana y alrededor del $60 \%$ de estos viajes son realizados en bicicleta entre las $06 \mathrm{h00}$ y 08h00. Con el nuevo proyecto de creación de ciclovías del Gobierno Municipal de Tulcán se espera que el número de viajes en este modo de transporte no motorizado se incremente.

Figura 29

Viajes en bicicleta por hora

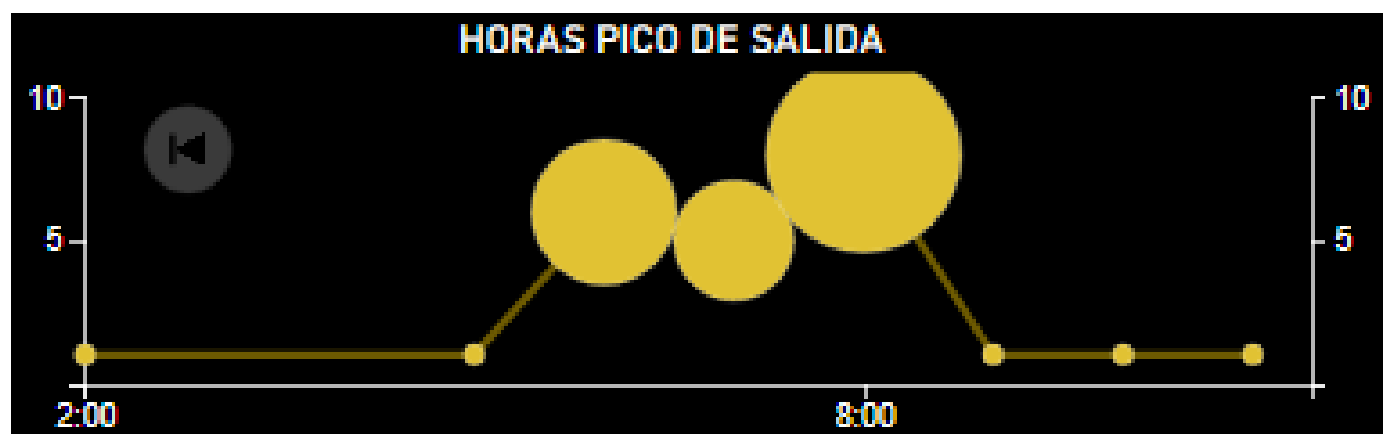

Fuente: Elaboración propia - Power BI Desktop

\subsection{Cuadro de mando dinámico de la movilidad de Tulcán}

Como resultado final del proyecto se integraron todos los indicadores analizados en un cuadro de mando que genera reportes de alto nivel visual e interactivo al que puede acceder el grupo de investigación del proyecto a través de una aplicación web y móvil desarrollada en Power Bl y que se encuentra sincronizada con la base de datos de movilidad y logística urbana creada para que se realicen actualizaciones periódicas de los reportes.

Figura 30

Interfaces móvil y web del cuadro de indicadores dinámico de la movilidad de Tulcán

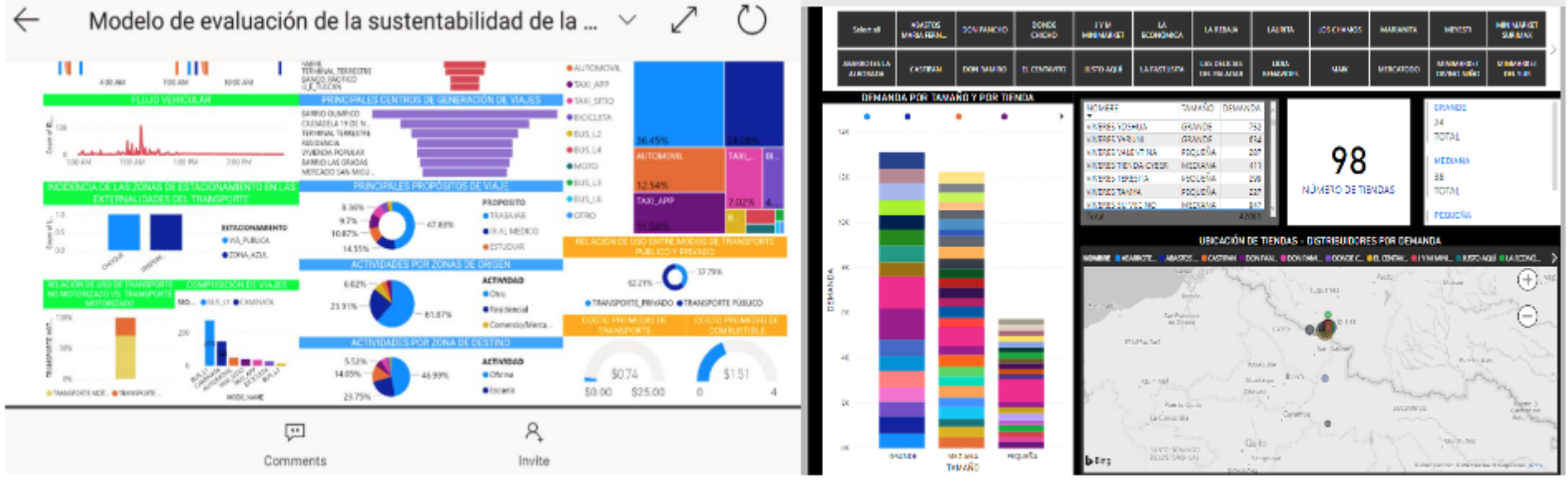

Fuente: Elaboración propia - Power BI, Power BI Mobile

\section{Conclusiones}

Las zonas que más generan y atraen viajes se encuentran en los sectores del centro y sur de la ciudad de Tulcán, donde se ubican zonas residenciales, comerciales y educativas. Son lugares con alta demanda de transporte: la UPEC, el parque central de la ciudad (donde se encuentran las principales instituciones públicas y privadas), la 
terminal de transporte, la aduana y todo el sector sur de la ciudad. Los costos generales de transporte tanto público como privado, generados principalmente por el consumo de combustible y proporcionales a la distancia de viaje recorrida, son relativamente bajos en comparación con otras ciudades, por lo que el transporte motorizado tiende a ser el más usado por la ciudadanía.

Se evidencia un alto uso del transporte de bus público en relación con los demás modos de transporte, por lo que las entidades competentes, así como las empresas de este sector, deberían buscar mejorar su servicio para que se siga incrementando su uso como resultado de ofrecer un servicio más atractivo a la ciudadanía. Además, la composición por viaje realizado en este transporte es mucho más alta, lo que implica un mejor uso de la infraestructura víal, reducción de la congestión y los flujos vehiculares y un aporte al cuidado del medio ambiente al tener menos vehículos circulando. Este aspecto es un factor determinante en la optimización de la sustentabilidad de la movilidad urbana.

El tamaño de la ciudad ha hecho que una buena parte de la ciudadanía opte por realizar sus viajes caminando, lo cual de igual forma es un aspecto muy favorable en la protección del medio ambiente y la mejora de la movilidad urbana. Es necesario, de esta forma, mejorar la seguridad vial para peatones, la señalización en calles y aceras, la iluminación y la estética general de la arquitectura urbana de la ciudad de Tulcán. Esto hará que las personas se vean más motivadas a realizar sus viajes relacionados con sus actividades diarias caminando o utilizando modos no motorizados como la bicicleta.

Un resultado destacado de la investigación fue que, si bien el número de externalidades en relación a la movilidad urbana es casi inexistente, las instancias generadas en este aspecto se dieron en los lugares de estacionamiento. Se deberían analizar las causas de este problema que, a primera vista, podría deberse a que se utilizan lugares sin el espacio adecuado para el parqueo y la circulación de los vehículos, señalética deficiente en zonas de estacionamientos y formas inadecuadas de parqueo, entre otros.

Se evidencia de forma destacada en los resultados que en la ciudad de Tulcán existe un equilibrio entre el uso de transporte público (buses y taxis) y los medios privados, un porcentaje alto de viajes realizados mediante caminata y una alta atracción de viajes en las zonas centro y sur de la ciudad, siendo el propósito principal de viaje las actividades laborales en oficina. Además, se pudo observar que las externalidades de transporte en el periodo de análisis son prácticamente inexistentes aunque se tienen flujos vehiculares altos en horas pico (07h00 a $08 \mathrm{~h} 00$ y $12 \mathrm{h00}$ a 14h00) en las calles principales del centro y sur de la ciudad debido, principalmente, a la alta circulación de vehículos livianos, el ancho reducido de las vías y el tamaño de los buses de transporte público, que bloquean el flujo vehicular en los lugares donde se encuentran las paradas. En función de estos resultados, se determinan la sustentabilidad y los criterios de mejora de la movilidad urbana en la ciudad de Tulcán.

\section{Referencias bibliográficas}

Alcántara Vasconcellos, E. (2010). Análisis de la movilidad urbana. Espacio, medio ambiente y equidad. Bogotá: CAF. Recuperado de: http://scioteca.caf.com/handle/123456789/414

de Dios Ortúzar, J. (2012). Modelos de demanda de transporte. Ediciones UC.

GADMT. (2020). Plan de ciclovías emergentes para la ciudad de Tulcán. 5-6. Recuperado de: https://www.gmtulcan.gob.ec/doc/PROYECTO\%20CICLOVIAS\%20EMERGENTES\%20CIUDAD\%20DE\%20TUL CAN.pdf

Gartor, M. (2015). El sistema de bicicletas públicas BiciQuito como alternativa de movilidad sustentable: aportes y limitaciones. Letras Verdes, (18), 249-263. doi: https://doi.org/10.17141/letrasverdes.18.2015.1639 
Hernandez Garcia, I., Hernández García, J., y Niño Bernal, R. (2012). Visiones alternas de ciudad: complejidad, sostenibilidad y cotidianidad. Bitácora urbano territorial. Recuperado de: https://repositorio.unal.edu.co/bitstream/handle/unal/36980/24780-114069-1-PB.pdf?sequence=1

Instituto Mexicano del Transporte. (2005). Enfoque económico para la corrección de "Externalidades" en el transporte. Recuperado de: https://imt.mx/resumen-boletines.html? IdArticulo=285\&IdBoletin=98\#: :text=Las\%20\%E2\%80\%9Cexternalidades\%E2\%80\%9D\%20en\%20el\%20tra nsporte,forma\%20de\%20beneficios\%20o\%20costos.

Instituto Nacional de Estadística y Censo (2021). Resultados del Censo 2010 de población y vivienda en el Ecuador, Fascículo provincial Carchi. Recuperado de: https://www.ecuadorencifras.gob.ec/wpcontent/descargas/Manu-lateral/Resultados-provinciales/carchi.pdf

Morillo Enríquez, T. M. (2020) La movilidad alternativa como medida de mitigación al cambio climático en el centro urbano de la ciudad de Tulcán. Recuperado de: https://repositorio.flacsoandes.edu.ec/bitstream/10469/16540/5/TFLACSO-2020TMME.pdf

Mura, H. G. C., y Reyes, J. I. P. (2015). De la sostenibilidad a la sustentabilidad. Modelo de desarrollo sustentable para su implementación en políticas y proyectos. Revista Escuela de Administración de Negocios, (78), 40-54. Recuperado de: https://www.redalyc.org/pdf/206/20640430004.pdf

Obregón-Biosca, S. A., y Betanzo-Quezada, E. (2015). Análisis de la movilidad urbana de una ciudad media mexicana, caso de estudio: Santiago de Querétaro. Economía, sociedad y territorio, 15(47), 61-98. Recuperado de: http://www.scielo.org.mx/pdf/est/v15n47/v15n47a4.pdf

Organización de las Naciones Unidas. (2021). Objetivos de Desarrollo Sostenible. Recuperado de: https://www.un.org/sustainabledevelopment/es/objetivos-de-desarrollo-sostenible/

Poole Fuller, E. (2017). ¿ Hacia una movilidad sustentable? Desafíos de las políticas de reordenamiento del transporte público en Latinoamérica. El caso de Lima. Letras Verdes, Revista Latinoamericana de Estudios Socioambientales, (21), 4-31. Recuperado de: http://scielo.senescyt.gob.ec/pdf/Iverdes/n21/1390-6631Iverdes-21-00004.pdf

Quinatoa Morocho, F. E. (2018). Sistemas OLTP de la Misión Scalabriniana de Ecuador y su incidencia en la gestión de reportes de ayuda y movilidad humana (tesis de maestría). Universidad Técnica de Ambato, Ecuador, 53-54, 71-76. Recuperado de: http://repositorio.uta.edu.ec/bitstream/123456789/27257/1/Tesis_\%20t1366mbd. pdf

Quintero-González, J. R. (2017). Del concepto de ingeniería de tránsito al de movilidad urbana sostenible. Ambiente y Desarrollo, 21(40), 57-72. https://doi.org/10.11144/ Javeriana.ayd21-40.citm doi:10.11144/Javeriana.ayd21-40.citm

Rivera Martín, E. R. (2019). Sistema de Business Intelligence de apoyo al proceso de toma de decisiones en la gestión de la movilidad turística y su relación con los alojamientos P2P en la Isla de Tenerife.3, 20-41. Recuperado de: https://riull.ull.es/xmlui/bitstream/handle/915/17569/Sistema\%20de\%20Business\%20Intelligence\%20de \%20apoyo\%20al\%20proceso\%20de\%20toma\%20de\%20decisiones\%20en\%20la\%20gestion\%20de\%20la\%2 Omovilidad\%20turistica\%20y\%20su\%20relacion\%20con\%20los\%20alojamientos\%20P2P\%20en\%20la\%20ls la\%20de\%20Tenerife.pdf?sequence=1\&isAllowed=y 


\section{Anexos}

\section{Cuadro 1}

Encuesta origen - destino: cuestionario de control

\section{ENCUESTA DE MOVILIDAD URBANA EN LA CIUDAD DE TULCÁN}
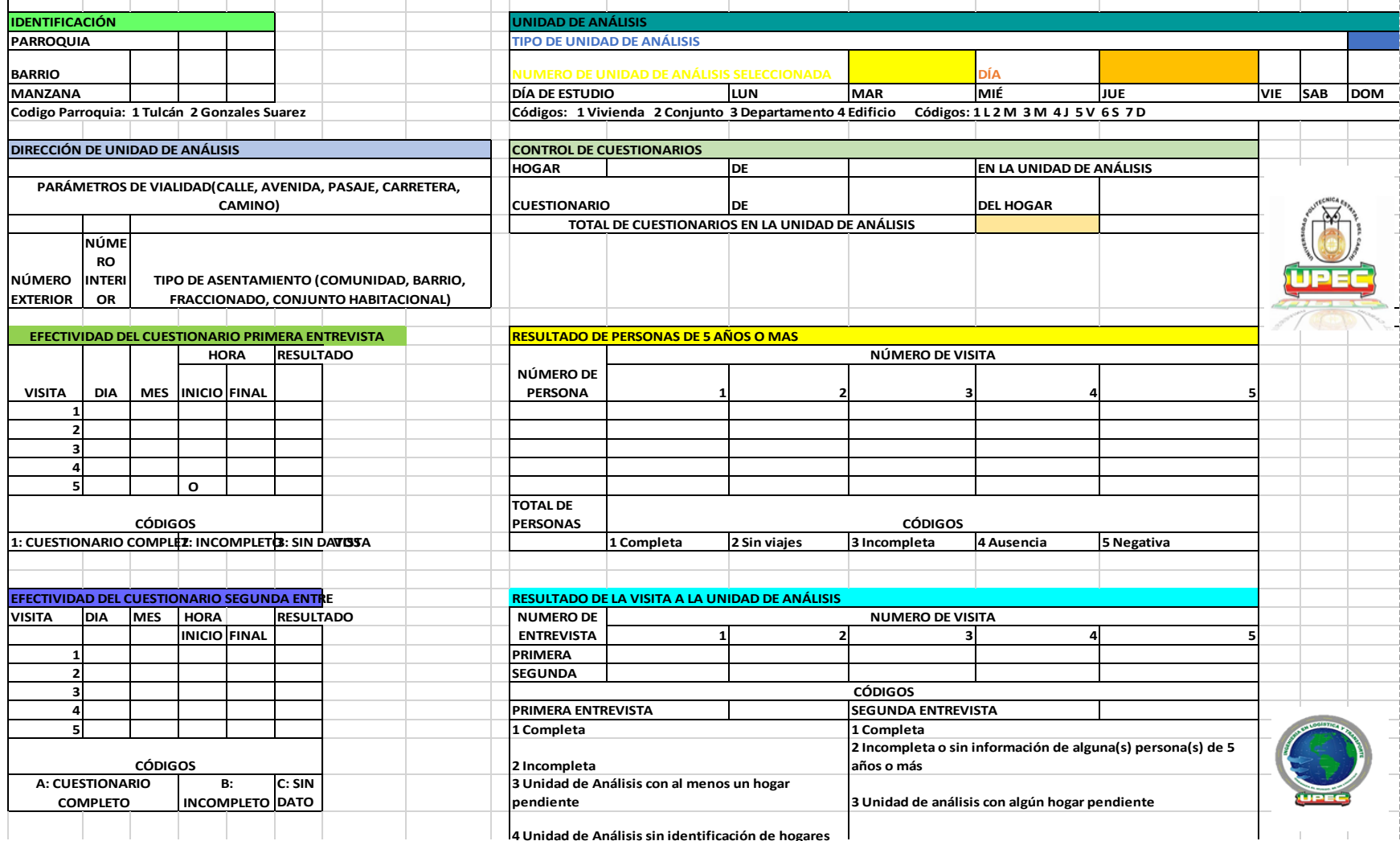

Fuente: Elaboración propia

\section{Cuadro 2}

Encuesta origen - destino: cuestionario de investigación (A)

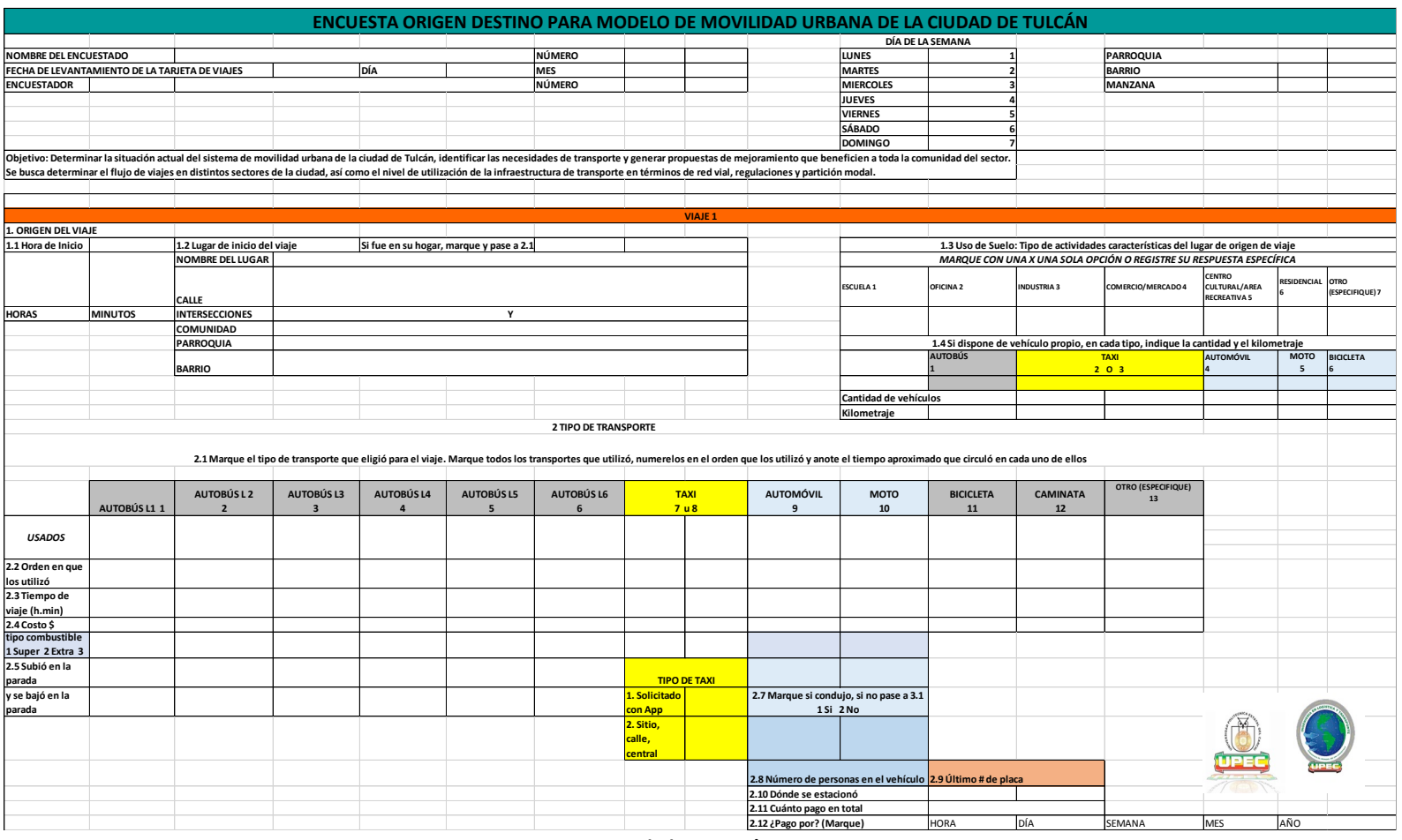

Fuente: Elaboración propia 
Cuadro 3

Encuesta origen - destino: cuestionario de investigación (B)

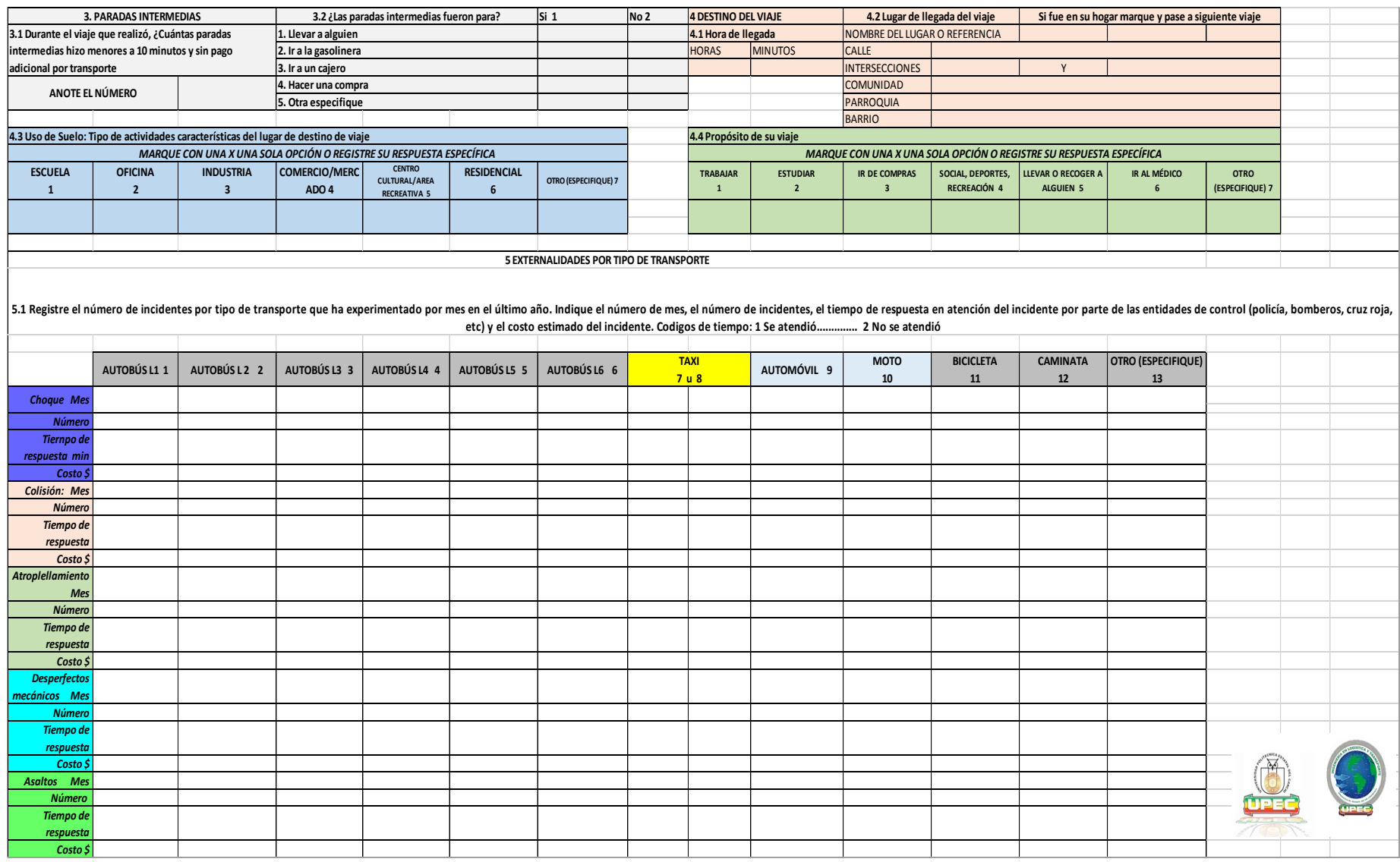

Fuente: Elaboración propia

Esta obra está bajo una Licencia Creative Commons Attribución-NoCommercial 4.0 International

(cc) EY-NG 